\author{
UNIVERSIDADE DE SÃO PAULO \\ ESCOLA DE EDUCAÇÃO FÍSICA E ESPORTE
}

\title{
EFEITO DA META DE APRENDIZAGEM NA AQUISIÇÃO DO GOLPE DE JUDÔ O SOTO GARI
}

Fernando Ikeda Tagusari

São Paulo

2019 


\author{
UNIVERSIDADE DE SÃO PAULO \\ ESCOLA DE EDUCAÇÃO FÍSICA E ESPORTE
}

\title{
EFEITO DA META DE APRENDIZAGEM NA AQUISIÇÃO DO GOLPE DE JUDÔ O SOTO GARI
}

Fernando Ikeda Tagusari

São Paulo

2019 
FERNANDO IKEDA TAGUSARI

\section{EFEITO DA META DE APRENDIZAGEM NA AQUISIÇÃO DO GOLPE DE JUDÔ O SOTO GARI}

\section{VERSÃO CORRIGIDA}

(versão original disponível no Setor de Biblioteca)

Dissertação apresentada à Escola de Educação Física e Esporte da Universidade de São Paulo, como requisito parcial para a obtenção do título de Mestre em Ciências.

Área de Concentração: Estudos Socioculturais e Comportamentais da Educação Física e Esporte.

Orientador: Prof. Dr. Go Tani

São Paulo

2019 
Catalogaçäo da Publicação

Serviço de Biblioteca

Escola de Educação Física e Esporte da Universidade de São Paulo

Tagusari, Fernando lkeda

Efeito da meta de aprendizagem na aquisiçäo do golpe de judô o soto gari / Fernando lkeda Tagusari. - Säo Paulo : [s.n.]. 2019.

$59 \mathrm{p}$.

Dissertaçäo (Mestrado) - Escola de Educaçäo Física e Esporte da Universidade de Säo Paulo.

Orientador: Prof. Dr. Go Tani

1. Aprendizagem motora 2. Judô 3. Luta I. Título. 


\section{FOLHA DE AVALIAÇÃO}

Autor: TAGUSARI, Fernando Ikeda

Título: EFEITO DA META DE APRENDIZAGEM NA AQUISIÇÃO DO GOLPE DE JUDÔ O SOTO GARI

Dissertação apresentada à Escola de

Educação Física e Esporte da

Universidade de São Paulo, como requisito parcial para a obtenção do título de Mestre em Ciências.

Data:

\section{Banca Examinadora}

Prof. Dr.:

Instituição: Julgamento:

Prof. Dr.:

Instituição: Julgamento:

Prof. Dr.:

Instituição: Julgamento: 
Dedico à minha amada avó, Kazue Ikeda (in memoriam).Saudades eternas. 


\section{AGRADECIMENTOS}

Ao Prof. Dr. Go Tani por todo ensinamento que prestou durante o processo de mestrado. Obrigado por ampliar minha visão e entendimento sobre o Judô, principalmente em questionar a forma tradicional na qual o Judô é ensinado e praticado.

Aos membros da banca, pelas contribuições não apenas para 0 aprimoramento deste estudo, mas também para o meu amadurecimento.

À minha família pelo apoio incondicional.

À Natalia Estrela, por estar sempre ao meu lado, incentivando-me a buscar novos desafios.

Aos amigos do LACOM, Fernando Garbeloto dos Santos e Ricardo Drews, por toda ajuda e apoio; aprendo muito com vocês.

Ao Colégio Aldeia dos Pandavas, por gentilmente ter disponibilizado seus alunos para participar deste estudo.

Ao meu mestre Massao Shinohara e todos os companheiros da Associação de Judô Vila Sônia.

Aos docentes do LACOM: Prof. Dr. Umberto Cesar Corrêa, Profa. Dra. Andrea Michele Freudenheim, Prof. Dr. Luciano Basso, Prof. Dr. Jorge Alberto de Oliveira, Profa. Dra. Camila Torriani-Passin e Prof. Dr. Flávio Henrique Bastos. 


\section{RESUMO}

TAGUSARI, F.I. Efeito da meta de aprendizagem na aquisição do golpe de Judô o soto gari: 2019. 59 f Dissertação (Mestrado em Ciências) - Escola de Educação Física e Esporte, Universidade de São Paulo, São Paulo. 2019.

De acordo com a Aprendizagem Motora, os golpes de Judô podem ser classificados como habilidades seriadas - implicam a realização de uma sequência de movimentos (componentes) que resulta no desequilíbrio (kuzushi), encaixe (tsukuri) e finalização (kake) do oponente - e abertas - o oponente se movimenta constantemente durante a luta. Tradicionalmente, as técnicas são ensinadas por meio do uchi komi que se caracteriza pela repetição de golpes sem a sua finalização e praticado com pouca ou nenhuma reação do oponente. Considerando a classificação dos golpes, o ensino por meio do uchi komi apresenta limitações por não levar em consideração o contexto da luta que é de natureza dual e dinâmica. $\mathrm{Na}$ área de estudos da Aprendizagem Motora, o problema de contexto tem sido investigado por meio da manipulação de dois tipos de meta: a da tarefa e a de aprendizagem. Aplicando-se esses dois tipos de meta à aprendizagem dos golpes de Judô tem-se que a meta da tarefa corresponde à meta do golpe em si e a meta de aprendizagem adiciona a essa meta a situação em que este golpe será utilizado, por exemplo, de shiai ou randori. Isto posto, o presente estudo investigou o efeito da meta de aprendizagem na aquisição do golpe o soto gari do Judô. Foi delineado um experimento constituído por 7 sessões de prática, divididas em: a) pré-teste, que ocorreu na $1^{1}$ sessão e objetivou a formação dos grupos experimentais; b) fase de aquisição, da $2^{\text {a }}$ à $6^{\text {a }}$ sessões, de prática do golpe 0 soto gari; c) teste de transferência imediato (TRi) na $6^{\underline{a}}$ sessão realizado imediatamente após a última sessão de prática; d) teste de transferência atrasado (TRa), realizado 7 dias após a 6 ${ }^{\text {a }}$ sessão. Os testes de transferência foram constituídos por uma situação de luta controlada. Os participantes $(n=24)$ foram distribuídos em dois grupos experimentais ( $n=12)$ : Grupo Meta da Tarefa (GMT) e Grupo Meta de Aprendizagem (GMA). Ambos os grupos receberam antes das sessões de prática instrução sobre a meta da tarefa. O GMA foi adicionalmente instruído que ao final das sessões de prática haveria uma luta na qual deveria projetar o oponente utilizando o golpe o soto gari. $\mathrm{Na}$ fase de aquisição, em cada bloco das sessões de prática, os participantes assistiram a 3 formas diferentes de executar o golpe o soto gari. Os praticantes 
foram livres para escolher dentre as 3 formas do golpe uma que iria praticar durante o bloco todo. As escolhas de cada participante foram registradas. Como medidas de desempenho nos testes de transferência foram consideradas: a) a quantidade de tentativas do golpe realizadas; b) em caso de sucesso na execução do golpe, esta foi avaliada seguindo os critérios estabelecidos pela Federação Internacional de Judô para pontuação. Os resultados mostraram que o GMA, ao receber a meta da aprendizagem, elaborou estratégias na escolha das formas de execução do golpe, apresentou superioridade em relação ao GMT na quantidade de tentativas do golpe e, no quesito pontuação, obteve melhora no TRa em comparação ao TRi.

Palavras-chave: Aprendizagem motora, Judô, Meta de aprendizagem. 


\section{ABSTRACT}

TAGUSARI, F.I. Effect of the learning goal on the acquisition of the Judo technique o soto gari: 2019. 59 f Dissertação (Mestrado em Ciências) - Escola de Educação Física e Esporte, Universidade de São Paulo, São Paulo. 2019.

According to Motor Learning, Judo techniques can be classified as serial skills - they imply the execution of a sequence of movements (components), resulting in unbalance (kuzushi), preparation (tsukuri) and finishing (kake) of the opponent - and open - the opponent constantly moves during the fight. Traditionally, those techniques are taught through the uchi komi, which is characterized by movement repetition that neglects the finishing phase of the throw and is practiced with little or no reaction from the opponent. Considering the classification of techniques, teaching through the uchi komi presents limitations by not taking into account the context of the fight which is dual and dynamic in nature. In the field of Motor Learning, the context problem has been investigated through the manipulation of two types of goals: task and learning goals. Applying these two types of goals to the learning of Judo technique, the task goal corresponds to the goal of the technique itself and the learning goal adds to this the situation in which this technique will be used, for example, shiai or randori. Thus, the present study investigated the effect of the learning goal on the acquisition of $o$ soto gari Judo technique. An experiment was designed consisting of 7 sessions, divided into: a) pre-test, occurred in the 1st session aimed at the formation of experimental groups; b) acquisition phase, from the 2nd to the 6th practice sessions of the o soto gari; c) immediate transfer test performed immediately after the 6th practice session; d) late transfer test, 7 days after the 6th session. The transfer tests consisted of a controlled fighting situation. Participants $(n=24)$ were divided into two experimental groups $(n=12)$ : Task Goal Group (GMT) and Learning Goal Group (GMA). Both groups received before the practice sessions instruction about the goal of the task. GMA was instructed additionally that at the end of practice sessions there would be a fight in which participants should project the opponent using the technique o soto gari. In the acquisition phase, in each block of the practice sessions, the participants watched 3 different ways of executing the technique o soto gari. The participants were free to choose among the 3 forms one that would practice during the whole block. The choices of each participant were recorded. As performance measures in the transfer 
tests the following were considered: a) the number of attempts of the technique made by participants; b) if successful in the execution of the technique (projection), it was evaluated applying the criteria established by the International Judo Federation for scoring. The results showed that GMA elaborated strategies in the choice of the execution forms of o soto gari, presented superiority in relation to GMT in the number of attempts and in relation to scoring an improvement in the TRa in comparison to the TRi.

Key words: Motor learning, Judo, Learning goal. 


\section{SUMÁRIO}

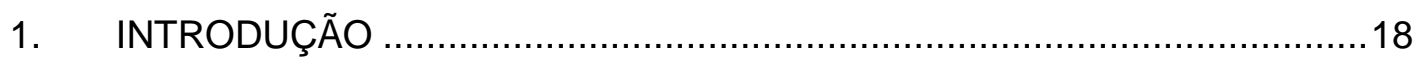

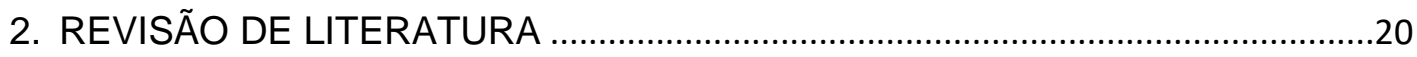

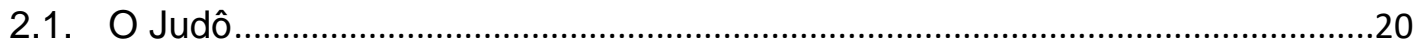

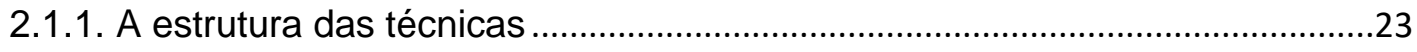

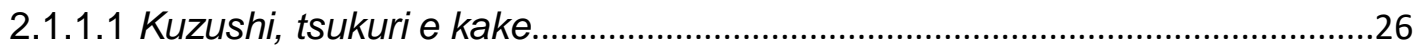

2.1.2. Classificação das habilidades motoras do Judô...............................................28

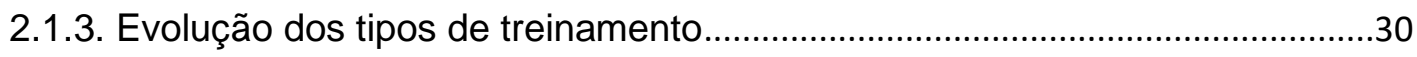

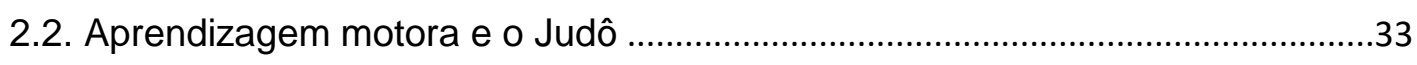

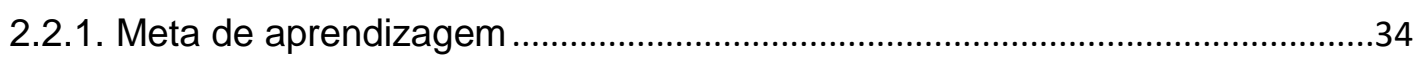

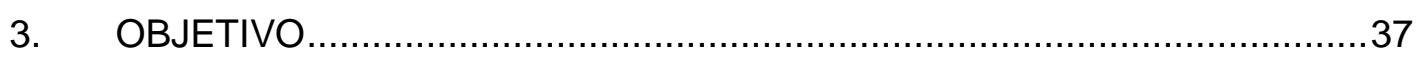

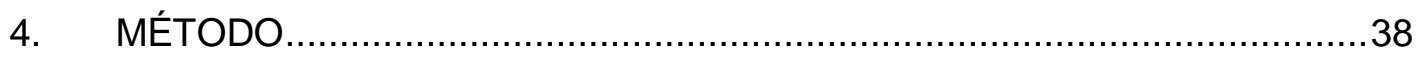

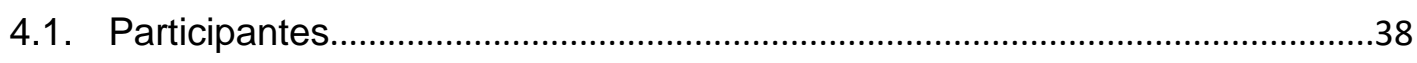

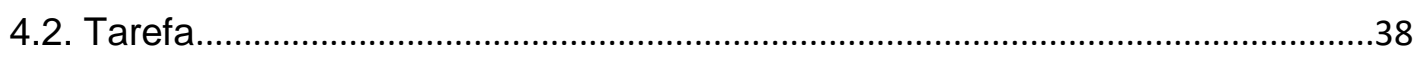

4.3. Delineamento experimental e procedimentos .....................................................40

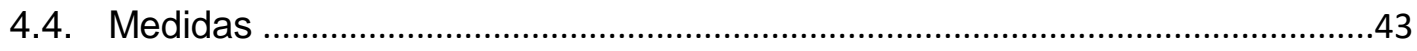

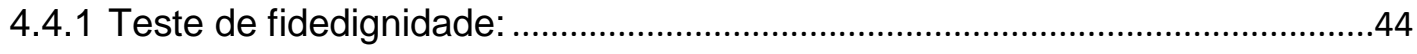

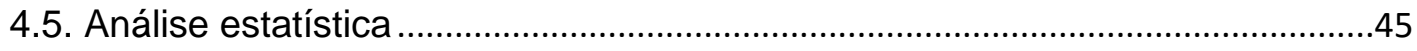

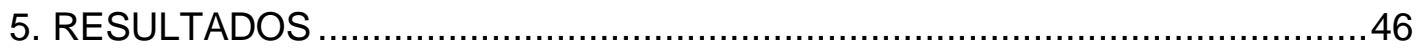

5.1. Número de tentativas de execução da técnica ....................................................46

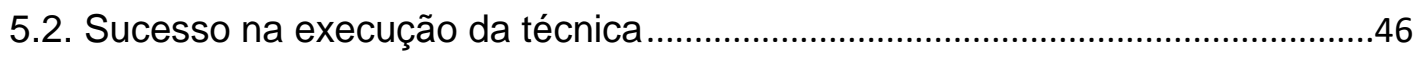

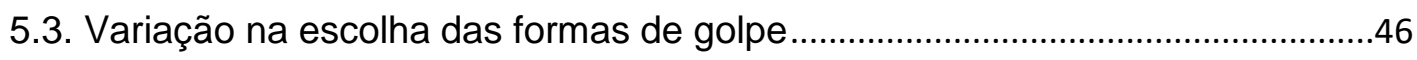

5.4. Desempenho intragrupo nos testes de transferência .........................................49

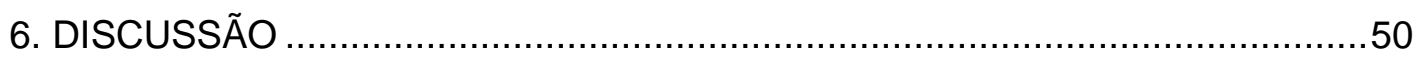

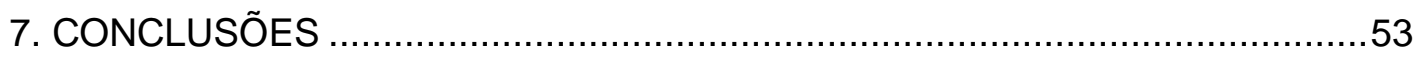

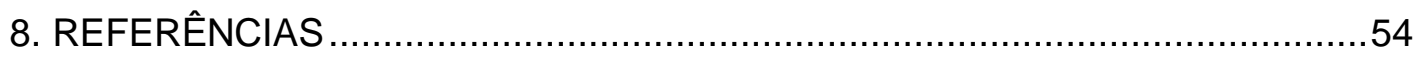




\section{LISTA DE FIGURAS}

Figura 1 - Classificação do nage waza........................................................ 24

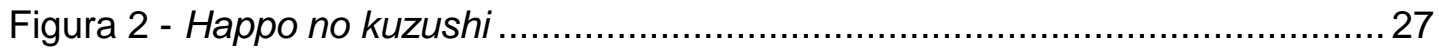

Figura 3 - Representação do uchi komi.......................................................... 39

Figura 4 - Segunda e terceira forma do golpe o soto gari.................................. 40 


\section{LISTA DE QUADROS}

Quadro 1 - Classificação das habilidades do judô conforme o processamento de informações. ............................................................................ 30 


\section{LISTA DE GRÁFICOS}

Gráfico 1 - Teste de Transferência Imediato - Medida Número de Tentativas 47

Gráfico 2 - Teste de Transferência Atrasado - Medida número de Tentativas. ...... 48

Gráfico 3 - Frequência de escolhas das formas.

49

Gráfico 4 - Comparação dos Testes de Transferências Imediato e Atrasado Medida

Pontuação. 


\section{LISTA DE TABELAS}

Tabela 1 - Sessões do ushiro ukemi

Tabela 2 - Sessões do experimento.

Tabela 3 - CEO obtido das medidas: pontuação obtida em caso de projeção e a quantidade de tentativas do golpe o soto gari. 


\section{LISTA DE ANEXOS}

Anexo 1 - Termo de consentimento livre e esclarecido .......................................5 57

Anexo 2 - Parecer consubstanciado do CEP.......................................................59

Anexo 3 - Protocolo de avaliação do golpe o soto gari....................................... 61 


\section{INTRODUÇÃO}

A meta do professor Jigoro Kano, ao criar o Judô, era a formação integral do indivíduo, não apenas a melhoria da aptidão física. Em outras palavras, a construção do caráter por meio da disciplina tanto mental como moral. Para atingir essa meta foram reorganizadas e reestruturadas diversas técnicas dos antigos estilos de Jujutsu (antiga arte marcial), com o objetivo de possibilitar a prática a todos. Essa reestruturação formou a base das técnicas hoje praticadas, constituída de três grandes grupos de golpes: atemi waza - técnicas que objetivam golpear os pontos vitais; nague waza - técnicas que objetivam projetar o adversário; katame waza técnicas que objetivam dominar o adversário. E, para a aquisição desses golpes, Kano (1994) estabeleceu duas formas de treinamento: kata - sistema de técnicas pré-definidas e pré-arranjadas - e randori - simulação de combate. O kata é o treinamento da base para o randori; através dele possibilita-se a compreensão dos componentes essenciais para a realização do golpe, mais especificamente as três fases do golpe: (1) kuzushi; (2) tsukuri; (3) kake, respectivamente, desequilíbrio, encaixe e finalização.

Na década de 1950, como consequência do processo de internacionalização do Judô e da popularização dos campeonatos, o modelo de treinamento estabelecido pelo professor Jigoro Kano foi reformado, omitindo-se o kata, enfatizando-se o randori e inserindo-se o shiai - competição (OTAKI; DRAEGER, 1990). Em substituição ao kata foi introduzido o uchi komi como base do ensino dos golpes. Uchi komi são formas pré-estabelecidas de treinamento, nas quais as técnicas são repetidas inúmeras vezes. Suas principais características são: a) foco na quantidade de prática (GOMES, 2007); b) não ocorre a projeção, portanto apenas as fases do kuzushi e tsukuri são praticadas; c) pode ser realizado sozinho - treino de sombra - ou com o auxílio de um uke - aquele que recebe o golpe - de modo estático ou em movimento; d) objetiva desenvolver a automatização do golpe e a velocidade na execução do mesmo.

Apesar de o uchi komi continuar a ser amplamente utilizado nos dias atuais, limitações acerca da sua eficácia têm sido apontadas, destacando-se duas delas: a) dificuldade em reproduzir os golpes aprendidos na situação de randori e/ou shiai 
(TAKAHASHI, 2005) - o uchi komi não atende às demandas de situações específicas (e.g. um golpe que exige uma determinada movimentação ou reação do uke); b) não contemplar a fase do kake (projeção), tornando o treinamento do golpe incompleto.

Ao se considerar os estudos de Aprendizagem Motora, pode-se dizer que a "tradição" inerente ao modo com que se ensinam as técnicas de Judô atualmente é contra produtiva. De acordo com os conhecimentos da Aprendizagem Motora, os golpes de Judô podem ser classificados como habilidades seriadas - implicam a realização de uma sequência de movimentos (componentes), que resulta no desequilíbrio, preparação e projeção do oponente (TAGUSARI; DOS SANTOS; TANI, 2016) - e abertas - o oponente se movimenta constantemente durante a luta. Ou seja, a falta da execução do golpe completo e a não movimentação podem prejudicar a aplicação do que é aprendido no uchi komi numa situação de luta. O ensino dos golpes de Judô busca alcançar dois objetivos principais: aprender a técnica almejando o seu uso em situação de luta e aprender o golpe objetivando a graduação de faixa, quando ele é demonstrado em forma de kata. O foco do presente estudo está no primeiro objetivo acima descrito, ou seja, na aprendizagem do golpe que será utilizado em situação de luta.

Considerando a questão do contexto da luta, o método tradicionalmente empregado no ensino dos golpes (uchi komi) pode ser questionado a partir dos conhecimentos da Aprendizagem Motora. Nesta área de investigação, o problema de contexto tem sido estudado por meio da manipulação de dois tipos de meta: a da tarefa e a de aprendizagem (BASTOS, 2010). De acordo com Bastos (2010), a meta da tarefa refere-se ao que o aprendiz deve ser capaz de fazer para obter sucesso na execução da tarefa motora. A meta de aprendizagem, por sua vez, adiciona à meta da tarefa o objetivo que o aprendiz busca alcançar com um conjunto de tentativas de prática. Ambas as metas não são mutuamente exclusivas, pois o praticante que possui uma meta de aprendizagem buscará a cada tentativa alcançar a meta da tarefa.

Para melhor compreender a meta da tarefa e a meta de aprendizagem, Bastos (2010) ilustra com uma situação hipotética de dois jovens aprendendo a rebatida no tênis de mesa. Ambos são instruídos a utilizar um robô lançador de bolas da forma que desejarem, de modo que a velocidade de lançamento das bolas é conhecida por eles. A meta da tarefa é informada para ambos, sendo esta a de 
rebater a bola para uma região específica da mesa do adversário. No entanto, um dos praticantes é estimulado a conseguir um bom resultado em todas as rebatidas da sessão de prática, enquanto o outro é informado de que, durante um jogo, é necessário responder as bolas em diferentes velocidades e que seria adequado preparar-se para essa situação durante a prática. É suposto que o primeiro aprendiz tenderá a focar no alcance da meta da tarefa, enquanto o outro, tendo recebido uma meta de aprendizagem procurará preparar-se para o contexto no qual deverá executar a habilidade.

Em síntese, o ensino dos golpes de Judô por meio do uchi komi não leva em consideração o contexto da luta que é de natureza dual e dinâmica, ou seja, os oponentes se movimentam constantemente procurando derrubar um ao outro por meio de diferentes golpes.

Aplicando-se esses dois tipos de meta à aprendizagem dos golpes de Judô tem-se a seguinte situação: a meta da tarefa corresponde à meta do golpe em si que é enfatizada no ensino tradicional por meio do uchi komi; a meta de aprendizagem adiciona a essa meta a situação (contexto) em que esse golpe será utilizado, por exemplo, de shiai ou randori. Assim, o objetivo do presente estudo foi investigar o efeito da meta de aprendizagem na aquisição do golpe o soto gari do Judô.

\section{REVISÃO DE LITERATURA}

\subsection{O Judô}

Do Jujutsu ao Judô

Qual a origem do Jujutsu? Segundo a tradição, no século XVII um homem chamado Chen Yuan Ping levou as técnicas do Jujutsu da China para o Japão. Três ronins (samurais sem mestre) - Fukuno Hichiroemon, Miura Yojiemon e Isogai Jirozaemon - foram inspirados pelos ensinamenos dele e desenvolveram um estilo próprio de Jujutsu. Em outras escolas, fala-se que um médico chamado Akiyama Shorobei, de Nagasaki, foi para a China e aprendeu o Hakuda, e ao retornar criou o Jujutsu. Existe outra teoria de que o Jujutsu começou na era dos deuses e é uma invenção puramente japonesa.

Minha opinião pessoal é que o Jujutsu foi criado inteiramente pelos japoneses.

(KANO, 2005, tradução nossa)

O professor Jigoro Kano acreditava que o Jujutsu foi criado inteiramente pelos japoneses. A teoria de que Akiyama Shorobei foi fundador do Jujutsu é somente difundida entre o grupo Yoshin ryu, talvez representando a história da criação deste 
estilo (KANO, 2005). A teoria de que Chen Yuan Ping foi o fundador do Jujutsu é muito difundida no Japão, porém pouco provável. Ping chegou ao Japão em 1659 e morreu em 1671; se ele trouxe o Jujutsu para o Japão foram os estilos Kenpo e/ou Hakuda, artes marciais praticadas na China. O Kenpo e Hakuda eram técnicas que envolviam basicamente chutes e empurrões, sendo improvável que tenham evoluído a um nível elevado quanto o Jujutsu japonês (KANO, 2005).

O Jujutsu tinha como objetivo o combate. A diferenciação entre os estilos era a maneira pela qual o combate era compreendido. Alguns estilos poderiam se utilizar de ataque aos pontos vitais para matar o oponente, ou capturar o oponente para depois matar. Apesar de o combate ser o objetivo principal não se pode descartar que o Jujutsu também promoveu indiretamente o treinamento do corpo. Era exigido um físico propício para a execução das técnicas e o treinamento cognitivo para traçar estratégia e/ou criar mecanismos para vencer em uma luta.

O Judô foi criado em fevereiro 1882 pelo então jovem Jigoro Kano com base nas técnicas oriundas das escolas do antigo Jujutsu, em especial a Kito Ryu e Tenshin Shinyo Ryu. As técnicas das antigas escolas de Jujutsu foram elencadas e reestruturadas com o objetivo de torná-las acessíveis para a prática de todos, modificando seus objetivos que não eram voltados para a educação física, moral ou intelectual. Dessa reestruturação das antigas escolas de Jujutsu originou-se o Kodokan Judô.

Para fomentar o Judô, o professor Jigoro Kano enfatizou os treinamentos físico e mental, mas excluiu do combate o fator de periculosidade.

Na transformação do Jujitsu ${ }^{1}$ para o Judô, há um significado profundo segundo o mestre [Jigoro Kano]. Ele próprio explica que, no antigo Jujitsu, o treinamento se resumia ao sistema de ataque e defesa, mas no Judô novo, embora os exercícios livres e précombinados fossem iguais aos do Jujitsu, a base de tudo estava no Dô - o caminho ou moral dando ênfase especial a isso. Portanto, no Judô, o jitsu - técnica ou arte - não passa de um meio para se ingressar num grande caminho. Para deixar isso bem claro, frisou ele, pôs o nome de Judô.

(SHINOHARA, 1982, p.8 - grifo nosso)

O objetivo do Kodokan Judô:

\footnotetext{
${ }^{1}$ Jujutsu e Jujitsu serão considerados sinônimos
} 
O objetivo do Judô é utilizar a força física e mental de forma mais eficaz. Sua formação é compreender o verdadeiro sentido da vida através do treinamento físico e mental de ataque e defesa.

(KANO, apud FUKUDA, 1973, p.9 - tradução nossa)

\begin{abstract}
A palavra Judô é escrita por dois ideogramas chineses, $J U$ - flexibilidade - e DO - caminho, portanto, de forma simplificada, o Judô pode ser traduzido como caminho suave.
\end{abstract}

Algumas pessoas perguntaram por que não usei um nome como Jurikagu (a ciência do Ju) ou Juriron (a teoria do $J u$ ) em vez de Judô. Foi uma questão de preferencia pessoal, Eu achei que os nomes Jurikagu e Jurion seriam tão inovadores que dariam a impressão de que eu inventei algo. Eu apenas queria garantir que as conquistas dos que se foram antes d emim não fossem perdidas. Assim, usei um nome que já existia e adicionei a ele o nome de meu dojo.

(KANO, 2005, tradução nossa)

Para Shinohara (1982), o conceito de suavidade pode ser ilustrado pelo distintivo da Kodokan, em que se mostra o vermelho do ferro incandescente envolto pela brancura do algodão, que significa "delicado por fora, forte por dentro". De posse desse conceito, a suavidade é demonstrada no Judô através de suas técnicas, em que se utiliza a força do adversário para vencê-lo (FUKUDA, 1973; KANO, 1994, 2005; SHINOHARA, 1982).

Gradativamente o Judô Kodokan foi ganhando popularidade ao passo que as escolas do antigo Jujutsu entraram em declínio a partir da Restauração Meiji. O sucesso do Judô Kodokan, o professor Jigoro Kano assim justifica:

A política educacional do passado era não ensinar a teoria no início para que depois os alunos praticassem as aplicações. Em vez disso, os instrutores ensinavam aos alunos as técnicas que haviam apreendido durante seu próprio aprendizado e esses pupilos passavam essas técnicas a seus alunos. Portanto, o princípio básico que serviria como objetivo principal do ensino não era claro. (...)

(...) Na Kodokan, estudamos e praticamos técnicas com o propósito de usar a energia mental e física da maneira mais eficiente possível para atingir objetivos, não importa quais sejam - eis o princípio básico do Judô. Portanto, as pessoas que passam por treinamento não imitam meramente as ações do mestre, nem praticam sem compreender as razões por trás do que estão fazendo; elas estudam os métodos e treinam de acordo com princípios detalhados.(...)

(...) Nos últimos tempos, como o Judô se tornou mais popular, em alguns casos faltam o método educacional e o espírito fundamental do Judô. Portanto, minha esperança é que aqueles que 
estão em treinamento, tanto quanto os instrutores, deem a devida atenção a essas questões.

(KANO, 2005)

Watanabe e Avakian (1997) buscam uma abordagem do Judô como manifestação humana que pode ser considerada uma arte por ser uma metodologia oriunda das realizações próprias e também ciência, pois implica no entendimento de diversas leis da natureza, como gravidade, momento, velocidade, transferência de peso, atrito, colaborando para o desenvolvimento da lógica dos praticantes.

Professor Jigoro Kano desejava divulgar o Judô pelo mundo, não medindo esforços para a sua realização, principalmente nos seus últimos anos de vida. Para tanto designou seus melhores discípulos do Instituto Kodokan para diferentes países (Koisume para Inglaterra; Ishiguro e Kawaishi para França, Bélgica, Espanha e Países Baixos; Maeda, Tomita, Satake, Ono e Ito para as Américas).

No Brasil, os professores Noboro Ogino, Ryuzo Ogawa, Sobei Tani, Takeo Yano, Yassuiti Ono, Yoshio Kihara são considerados alguns dos principais precursores do Judô (FPJ, 2014). Após a Segunda Guerra Mundial, a modalidade foi institucionalizada, transformando-se em um esporte com características próprias e amplamente praticado. Como força propulsora desse processo de "esportivização" e massificação pode-se citar a entrada do Judô no cenário olímpico, em 1964, nos Jogos de Tóquio, como modalidade "teste" e, finalmente em 1972 nos Jogos de Munique, como modalidade efetiva, permanecendo até os dias de hoje (NUNES; RÚBIO, 2012). Em razão desse processo de "esportivização", o objetivo de formação integral do indivíduo foi sendo paulatinamente substituído por resultados em competições. Uma das consequências do foco nos resultados em competições é a pobreza técnica observada atualmente nas lutas de Judô, prevalecendo a força muscular e o vigor físico sendo raras as lutas em que se observa troca de golpes com elevada demonstração de habilidade (GOMES; PEROTTI Jr.; TANI, 2016).

\subsubsection{A estrutura das técnicas}

O repertório de técnicas do Judô é proveniente de duas escolas de Jujutsu estudadas por Jigoro Kano: a Tenshin Shin'yo, que contribuiu com as técnicas de katame waza - técnicas de submissão, de atemi waza - técnicas de soco e chutes e 
de kappo - técnicas de primeiros socorros; e a Kito Ryu, que contribuiu com o princípio do kuzushi - desequilíbrio, o nage waza - técnicas de projeção e o atemi waza.

O Kodokan Judô preconiza as técnicas de nage waza que são classificadas conforme mostra o esquema a seguir (Figura 1).

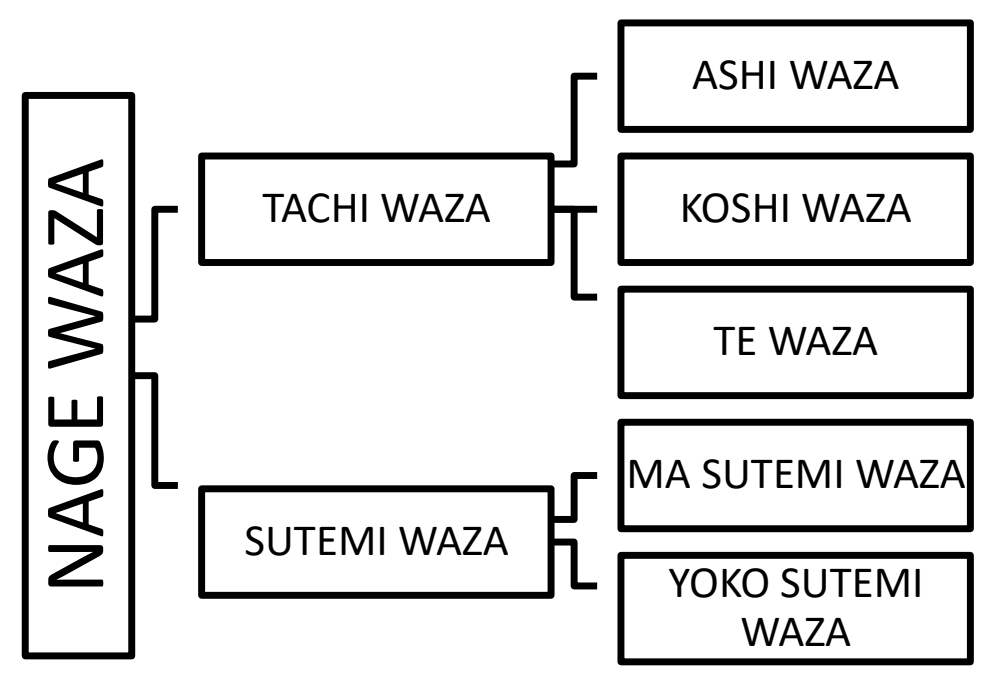

Figura 1 - Classificação do nage waza (KANO, 1994).

Atualmente são consideradas 68 técnicas pertencentes ao nage waza, divididas em duas categorias: tachi waza (projeção "em pé") e sutemi waza (técnicas de sacrifício). No tachi waza, as técnicas são classificas em: te waza (técnicas aplicadas com as mãos/braços), ashi waza (técnicas aplicadas com os pés/pernas) e koshi waza (técnicas aplicadas com quadril). A classificação em te, ashi e koshi representa a parte do corpo que desempenha papel central na execução da técnica (KANO, 1994), respectivamente, braço, perna e quadril. As técnicas de sutemi waza (técnicas de sacrifício) recebem esse nome porque o executante "sacrifica" sua posição de estabilidade projetando-se ao solo para derrubar o adversário. São divididas em duas categorias: ma sutemi waza (técnicas de sacrifício frontal) e yoko sutemi waza (técnicas de sacrifício lateral). Essa classificação é baseada na posição em que o tori se projeta ao solo: ma sutemi waza em decúbito dorsal e yoko sutemi waza em decúbito lateral (KANO, 1994). 
Os golpes do Judô podem ser considerados como um sistema em que a caracterização de cada técnica se faz pela organização de diversos componentes que serão executados em cada fase do golpe. Em cada movimento existe a interação entre o tori e o uke, ou seja, o sincronismo entre ação e reação (TAGUSARI; DOS SANTOS; TANI, 2016). São três as fases sequenciais e interdependentes que constituem os golpes, cada qual com características distintas: o kuzushi é a arte de "romper" o equilíbrio do adversário e forçá-lo para uma posição vulnerável; o tsukuri corresponde ao correto posicionamento do corpo de quem irá executar a técnica em relação ao adversário após ter realizado o desequilíbrio; e o kake é a finalização da técnica propriamente dita (MIFUNE, 2004). Todas as técnicas do Judô obedecem ao princípio do Seiryoku Zen'yo - princípio da máxima eficiência no uso da força - enfatizado na fase do kuzushi, em que o adversário é desequilibrado impossibilitando ou reduzindo qualquer tipo de reação (KANO, 2005).

As diversas situações nas quais o adversário é desequilibrado e, por consequência, projetado, podem ser demonstradas por meio do princípio do "Mitsu no Sen" (três momentos de ataque): sensen no sen (ante ataque: o ataque é realizado antes de qualquer reação do adversário), sen no sen (pré-ataque: o ataque é realizado antes que o adversário possa concluir sua técnica) e go no sen (contraataque: o ataque é realizado após a defesa da técnica do adversário) (BULL, 2005; DAIGO, 2005). Esses três momentos de ataque estão correlacionados diretamente com a ação do adversário e isso demonstra que a criação das artes marciais japonesas, em especial o Judô, está intimamente relacionada com o sentido de ataque e defesa (BULL, 2005; DAIGO, 2005; FUKUDA, 1973, 2003; KANO 1994, 2005; MIFUNE, 2004). Em linhas gerais, a "escolha" da defesa dependerá diretamente do ataque do adversário ou da sua ação esboçada.

Segundo Gomes, Perotti Jr., e Tani (2016), em uma luta de Judô há duas possiblidades de aplicar uma técnica de projeção: a) colocar o oponente em posição de desequilíbrio para posteriormente aplicar a técnica; b) aproveitar-se de um desequilíbrio ocorrido para aplicar a técnica mais adequada para a situação. $\mathrm{O}$ desequilíbrio é essencial para o sucesso da projeção do oponente ao solo.

O kuzushi pode ser compreendido como parte variante dos golpes - uma mesma direção ou situação de desequilíbrio pode possibilitar diferentes golpes. Já o tsukuri e kake são invariantes, pois são específicos de cada golpe (GOMES; 
PEROTTI Jr.; TANI, 2016). Há a possibilidade de conceber o kuzushi como uma capacidade mais genérica, incluindo os movimentos de deslocamento preparatórios para provocar o desequilíbrio no oponente (GOMES; PEROTTI Jr.; TANI, 2016).

\subsubsection{Kuzushi, tsukuri e kake}

São três as fases essenciais de execução das técnicas de projeção do Judô (KANO, 1994).

\section{O kuzushi}

As técnicas de projeção do Judô foram inspiradas nas clássicas escolas de Jujutsu, mais precisamente no estilo Kito Ryu, estilo do qual o professor Jigoro Kano desenvolveu apreço pelo kuzushi. Inicialmente o kuzushi continha apenas seis direções para o desequilíbrio (roppo no kuzushı); posteriormente é adicionado os desequilíbrios para os lados direito e esquerdo, totalizando oito direções (happo no kuzushi) (Figura 2). Esta classificação é utilizada até os dias de hoje (JONES, 2018).

A realização do kuzushi depende das circunstâncias da luta, como: a) maai (distância de combate); b) debana (oportunidade); c) ação indireta do tori (quem aplica a técnica), por exemplo, tai sabaki (movimentação corporal); d) ação direta do tori, por exemplo, puxar ou empurrar de acordo com o happo no kuzushi; e) hando no kuzushi (desequilíbrio por reação) geralmente proveniente de uma combinação de técnicas, na qual a primeira técnica resulta em um posicionamento que favorece o kuzushi da segunda técnica; f) kaeshi waza (contra ataque) em que o uke (quem será projetado) realiza uma técnica falha que será defendida e contra atacada pelo tori. O kuzushi não é limitado ao corpo do uke, podendo assumir o aspecto mental quando a concentração do uke é interrompida, produzindo uma oportunidade de ataque (JONES, 2018), por exemplo, no koshiki no kata (formas antigas) na técnica Ryusetsu (neve no salgueiro) é utilizado o movimento chamado kasumi (névoa) que objetiva atrair a atenção do uke para as mãos do tori. 

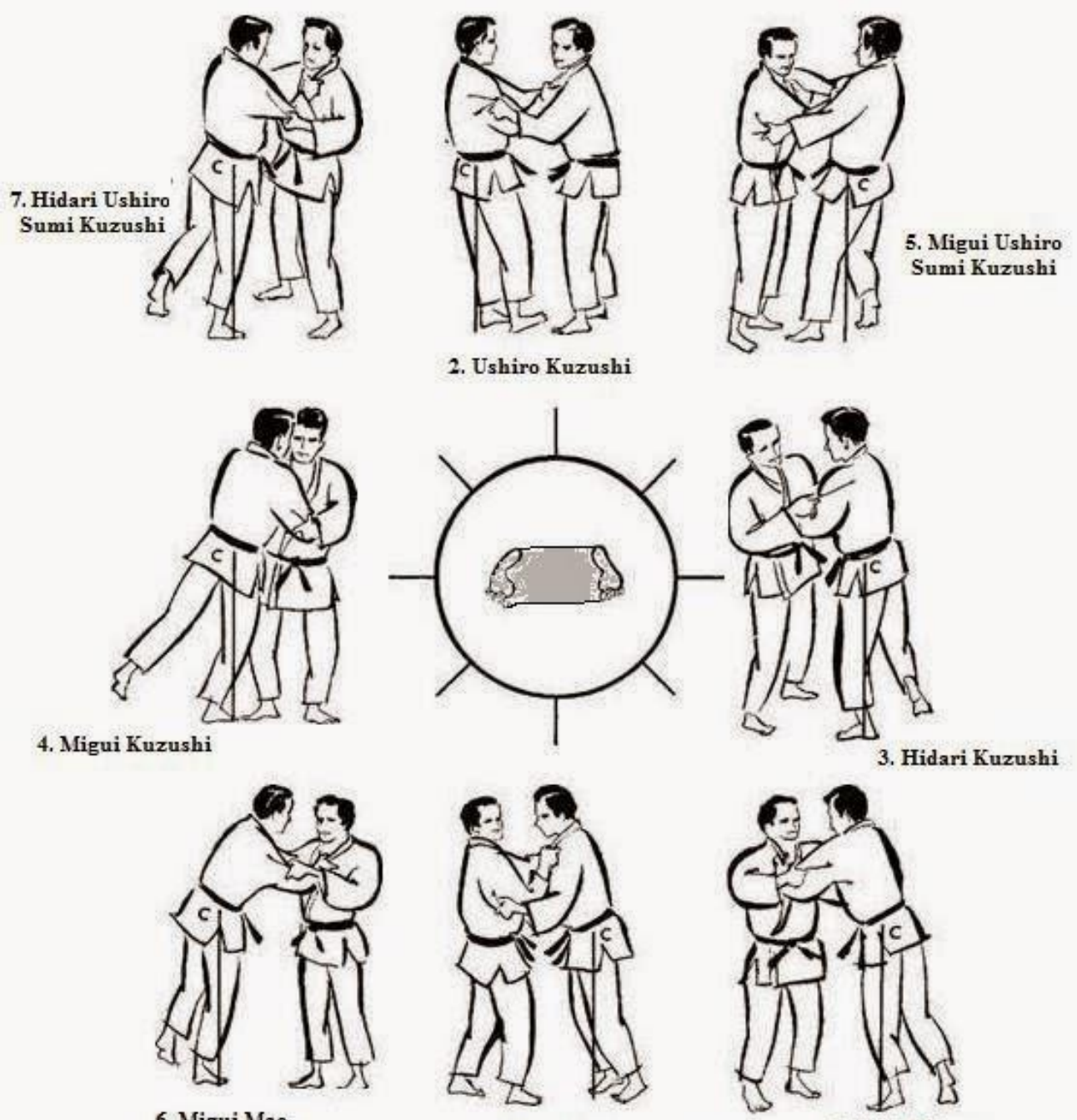

6. Migui Mae

1. Mae Kuzushi

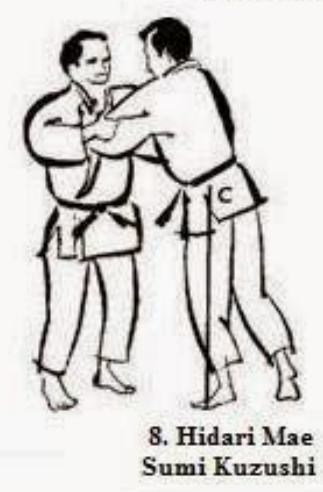

Figura 2 - Happo no kuzushi

O tsukuri

Uma vez realizado o kuzushi, inicia-se a fase do tsukuri que são os movimentos iniciais ou preparatórios para a projeção. A ação de preparação pode ser dividida em: a) aite no tsukuri (preparação do oponente) que consiste em posicionar o uke em uma postura que favoreça a projeção; b) jibun no tsukuri (preparação de si) que consiste em assumir uma postura e posição que favoreça a aplicação da técnica (JONES, 2018). 


\section{O kake}

É a continuação do tsukuri, culminando com a projeção do uke. Abe (2015, apud JONES, 2018) explica que para um bom kake é importante buscar a unidade das ações do corpo e mente, combinando o tsukuri e o kake na mesma ação. Em outras palavras, a unidade das ações do corpo e mente refere-se à automatização do movimento e a combinação do tsukuri e o kake remete a fluidez.

Para a ação da técnica de Judô é necessário que o tori realize de maneira coordenada, harmônica e sequenciada os movimentos, posicionando-se de uma forma adequada e finalizando o golpe. Possível devido ao processamento de informações realizado pelo sistema nervoso central, em que com base na análise de estímulos oriundos das mais diversas fontes, o tori é capaz de perceber as demandas ambientais, escolher o golpe adequado e por fim coordenar a execução do golpe propriamente dito. Quando executado com proficiência, é considerado que a habilidade motora foi adquirida.

\subsubsection{Classificação das habilidades motoras do Judô}

As habilidades motoras são ações que exigem o movimento voluntário e organizado do corpo ou membros para atingir um objetivo (TEIXEIRA, 2006; MAGILL, 2011) e devem ser aprendidas serem executadas de maneira adequada (TANI, 2006). Mas, elas podem ser entendidas também como tarefas motoras. De acordo com Schmidt e Wrisberg (2001), Teixeira (2006) e Magill (2011) as habilidades motoras como tarefas motoras podem ser classificadas como discretas em que o início e o final do movimento são facilmente reconhecidos. Quando uma habilidade envolve movimentos discretos executados em sequência elas são denominadas de seriadas. De acordo com essa classificação, os golpes do Judô são classificados como habilidades motoras seriadas, sendo constituídos por uma série de movimentos voluntários que envolvem o desequilíbrio, o encaixe e a finalização do golpe, respectivamente, o kuzushi, o tsukuri e o kake.

As habilidades motoras podem ser classificadas de acordo com a característica do ambiente em que elas são executadas. Dependendo de sua estabilidade, elas podem ser classificadas como abertas e fechadas. Neste sistema de classificação, o termo ambiente se refere especificamente ao meio sobre o qual a pessoa está agindo ou às características do contexto no qual a pessoa realiza a 
habilidade (MAGILL, 2011). São consideradas habilidades motoras fechadas quando o ambiente for estável, ou seja, se ele não se altera enquanto a pessoa estiver executando a habilidade; em contrapartida as habilidades motoras abertas são desempenhadas em um ambiente não estável, no qual o objeto ou o contexto varia durante a execução da habilidade - o participante deve agir de acordo com a ação do objeto ou das características de alteração do ambiente (MAGILL, 2011). Essa classificação é importante para o Judô, pois tem importantes implicações no ensino (Quadro 1). Por exemplo, na realização do uchi komi, quando o parceiro está parado, significa que a habilidade a ser adquirida está sendo concebida como fechada; por outro lado, quando realizado com o parceiro em movimento ou em forma de randori (luta de treinamento), a habilidade está sendo concebida como aberta. No primeiro caso, o aprendiz não precisa ajustar os movimentos às condições variáveis na execução da habilidade. Já no segundo, o aprendiz precisa sincronizar o tempo de início da ação motora com o movimento do seu companheiro (GOMES; PEROTTI Jr.; TANI, 2016). 


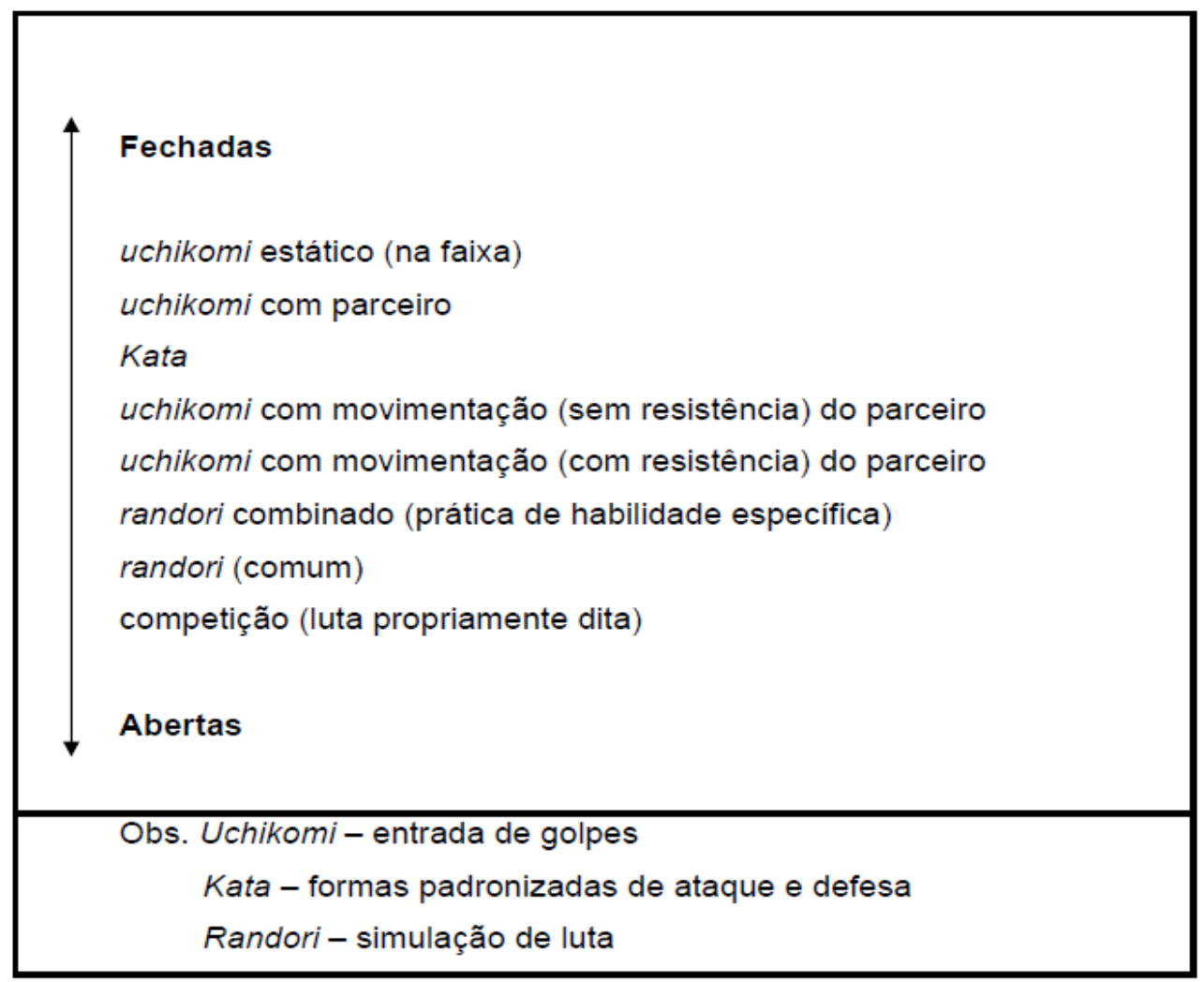

Quadro 1 - Classificação das habilidades do judô conforme o processamento de informações (Adams \& Carter, 1988; Franchini, 1998, 2001, apud Gomes, 2007).

A classificação de habilidades tem fortes implicações no método de ensino. As habilidades do Judô são abertas em razão de sua natureza dual, e o método de ensino tradicionalmente empregado é o uchi komi parado, cujo ensino se apoia em dois argumentos principais: a) reduzir o nível de dificuldade da tarefa para os alunos; b) promover a automatização do golpe por meio da repetição mecânica de movimentos. Uma limitação desse método é a perda da validade ecológica, ou seja, a aquisição de habilidade está ocorrendo sem relação com a especificidade da luta (GOMES; PEROTTI Jr.; TANI, 2016).

\subsubsection{Evolução dos tipos de treinamento}

No início, a quantidade de alunos do recém-formado Instituto Kodokan não passava de algumas dezenas, aos quais as técnicas eram ensinadas durante a prática do randori. Com o aumento do número de praticantes, o professor Jigoro Kano percebeu que o ensino das técnicas durante o randori era contraproducente, e 
assim, como solução, foram criados os kata (OTAKI; DRAEGER, 1990). Kata, em tradução literal, significa forma, que dentre várias interpretações existentes pode ser conceituada como "modo sob o qual uma coisa existe ou se manifesta"; modo, nesse caso, pode ser concebido como "maneira ou forma particular de fazer as coisas 3 ". Considerando essas definições, pode-se conceber, no contexto do Judô, o kata sob duas óticas: como um sistema de técnicas pré-definidas e pré-arranjadas os oito katas do Judô - e como o padrão dos movimentos existentes no Judô técnicas, posturas, passadas, etc. Sendo assim, o repertório técnico, ou seja, os golpes em si, são também considerados kata.

Aprender kata é semelhante a aprender gramática para o estudo da escrita, e a prática do randori é semelhante à prática da escrita entre si. Em outras palavras, para escrever uma redação, é necessário o conhecimento da gramática. Do mesmo modo para praticar bem o randori, é necessário o conhecimento do kata. Além disso, por mais que um indivíduo domine a gramática, isso não pressupõe que ele vá produzir uma boa literatura. Por outro lado, se o indivíduo tem apenas conhecimento limitado da gramática, não consegue escrever bem de jeito nenhum. Esse princípio vale também para o Jujutsu, se não estudarmos kata, poderemos até chegar a aprender métodos de defesa e ataque, mas não chegaremos a maestria.

(WATSON, 2011, p.121)

O kata e o randori são os pilares do modelo de treinamento do Judô tradicional. Segundo Kano (1994), o Judô tradicional prescreve a utilização do kata para o treinamento do fundamento de ataque e defesa e o randori para a simulação de um combate. Além do kata e do randori, Kano (2005) adiciona mais dois componentes para o ensino do Judô: a) Kougi (palestra) sobre os princípios do Judô, em que os treinamentos para competições e combates eram aprimorados mediante o ensinamento teórico por meio de palestras; b) Mondo (perguntas e respostas), que ocorria entre os alunos e o professor, uma ferramenta para reforçar a aprendizagem do Judô.

Otaki e Draeger (1983) alertam sobre uma crença bastante difundida a respeito da prática do kata com o objetivo de refinamento técnico e perfeição técnica. Estes são apenas um componente menor da prática dos katas, já que a técnica pode ser aperfeiçoada de outro modo (randori).

\footnotetext{
${ }^{2}$ Fonte: http://michaelis.uol.com.br/moderno/portugues/index.php?lingua=portuguesportugues\&palavra=forma, (acesso em 04/04/2017).

${ }^{3}$ http://michaelis.uol.com.br/moderno/portugues/definicao/modo\%20_1003250.html, (acesso em 04/04/2017).
} 
O Instituto Kodokan foi gradativamente ganhando popularidade. Kano (2005) atribui o sucesso do Judô ao método de ensino por ele fomentado: primeiro ensinar a teoria e os mecanismos das técnicas, posteriormente as suas aplicações. No entanto, não se pode atribuir o sucesso apenas ao método de ensino; deve-se, também considerar na expansão do Judô a competição como um agente propulsor.

Sabe-se que a competição é inerente ao Judô, não sendo possível aprimorar ou adquirir novas técnicas sem a presença do oponente (MIFUNE, 2004). Todavia, a sua importância foi mudando gradativamente; a princípio era uma maneira de promover o Judô, mas com o tempo se tornou o objetivo pelo qual o Judô é treinado, processo conhecido como a sua "esportivização".

No processo de "esportivização" do Judô podem-se destacar dois pontos no tempo: a década de 1950, que representa o início desse processo como consequência da criação dos campeonatos mundiais; o segundo, que em decorrência do primeiro, ascendeu o Judô como esporte olímpico, em 1972. A partir desses marcos o Judô assume as características do esporte de rendimento assim definido por Tani (1996): objetiva o máximo em termos de rendimento; visa a competição; ocupa-se com o talento e, portanto, preocupa-se com o potencial das pessoas, tornando-se seletivo e excludente; é voltado para especificidade; enfatiza o produto e resulta em constante inovação técnica. Em outras palavras, a prática do Judô passou não mais a ser direcionada prioritariamente para a formação integral do indivíduo, mas sim para o resultado nas competições.

O processo de "esportivização" do Judô alterou não apenas o objetivo do treinamento, mas o treinamento em si. Segundo Otaki e Draeger (1990), na expansão do Judô para o Ocidente, o significado do kata não foi bem compreendido e, como consequência, a sua prática foi substituída pelo uchi komi.

O uchi komi não foi originalmente previsto pelo professor Jigoro Kano. É incerto quando ele foi incorporado ao treinamento do Judô. Pensa-se que seja uma prática oriunda de outras artes marciais como o Kendo - o uchi komi gueiko, que consiste na repetição de ataques em locais específicos. No treinamento atual do Judô, o uchi komi é utilizado para o ensino das técnicas em substituição ao kata, o randori é utilizado para simular uma luta e o shiai é a competição propriamente dita (OTAKI; DRAEGER, 1990). 
Duarte (2015) defende a utilização do uchi komi como aprendizagem do golpe porque ele sintetiza, por meio da prática, todas as informações técnicas que compõem a complexidade de um golpe, possibilitando o aprendizado em todas as dimensões. Afirma, ainda, que a boa execução do golpe, tanto no randori quanto no shiai, depende da prática do uchi komi. Os argumentos do autor desconsideram as características das habilidades do Judô e o contexto no qual serão aplicadas. No entanto ilustra o método tradicional de ensino, no qual os professores ministram as suas aulas reproduzindo o método aprendido durante sua formação baseados em procedimentos empíricos historicamente disseminados (GOMES; PEROTTI Jr.; TANI, 2016).

Gomes (2007) aponta que o uchi komi mostra importantes limitações para o ensino dos golpes: a) não há projeção, portanto não contempla a fase do kake; b) se realizado sem movimentação não considera os elementos da fase do kuzushi; c) não considera a interdependência e sequenciamento das fases do golpe, consequentemente, os elementos que conectam uma fase a outra não são trabalhados, resultando na ineficiência da técnica; d) essas limitações resultam em projeções ineficientes - baixa ou nenhuma pontuação (em caso de competição), esforço excessivo e deficiência técnica. Estas limitações e eventuais soluções podem ser investigadas à luz da Aprendizagem Motora.

\subsection{Aprendizagem motora e o Judô}

A Aprendizagem Motora pode ser definida como um campo de investigação relacionado ao estudo dos mecanismos e processos subjacentes à mudança no comportamento motor de um indivíduo como resultado da prática. A mudança no comportamento está relacionada com a melhora na capacidade de solucionar problemas motores, ou seja, aquisição de habilidades motoras (TANI, 2006), e esse processo é influenciado por vários fatores.

A aprendizagem dos golpes do Judô envolve vários processos. Em primeiro lugar a compreensão dos componentes do golpe. Em segundo lugar a execução de cada componente utilizando diversos seguimentos do corpo. Isto implica inúmeros graus de liberdade - número de elementos ou componentes independentes num sistema de controle (MAGILL, 2011). De fato, um dos maiores desafios para 0 praticante é controlar os graus de liberdade para possibilitar a execução da 
habilidade (SCHMIDT; LEE, 2005). Em terceiro lugar, a utilização do golpe de maneira habilidosa em diversas situações de luta. Para Tani (2005), um indivíduo habilidoso é capaz de adaptar-se às perturbações alterando os parâmetros do movimento como força, velocidade e direção, ou alterando a própria estrutura do movimento como a ordem sequencial dos seus componentes. No Judô esta capacidade de adaptação é fundamental, em virtude da sua natureza dual.

No Judô, as orientações para a execução do uchi komi - forma, técnica, cadência e variação - são ditadas e corrigidas, com pouca ou nenhuma escolha por parte do aprendiz e o ambiente é predominantemente estável. Por outro lado, o randori ocorre numa situação dual, com sucessivos ataques e defesas em que o praticante processa as informações ambientais, escolhe e executa a técnica, de acordo com os movimentos do oponente. Portanto, a aprendizagem motora no Judô envolve não apenas ao alcance da meta da tarefa (execução do golpe), mas também a compreensão do contexto em que os golpes são executados. Ademais, na compreensão deste contexto que é essencialmente variável, pensa-se ser importante a presença de liberdade para tomar decisões para fazer escolhas mais adequadas à situação, ou seja, desenvolver estratégias de aprendizagem.

\subsubsection{Meta de aprendizagem}

Recentemente, estudos do processo de aquisição de habilidades motoras têm focado o autocontrole de algum aspecto da prática por parte do aprendiz (SANLI et al., 2013). As pesquisas sugerem que fornecer ao aprendiz o controle de algum aspecto da prática é mais benéfico para a aprendizagem comparado com condições externamente controladas (WULF, 2007).

Em uma condição autocontrolada, o desempenho dos aprendizes pode estar associado a elaboração de estratégias de aprendizagem (BASTOS, 2010). Na elaboração dessa estratégia, a meta de aprendizagem é um elemento que orienta o comportamento do aprendiz, em outras palavras, é a referência para a qual as estratégias de aprendizagem são elaboradas pelos aprendizes.

Sobre o efeito da meta de aprendizagem em condição autocontrolada, Bastos (2010), em um estudo pioneiro, verificou se o fato de dizer aos aprendizes o que irão realizar após o período de prática, leva-os a elaborar estratégias que beneficiam a 
aprendizagem de uma habilidade motora. A tarefa consistiu em pressionar a barra de espaços de um teclado de computador em sincronia com a chegada de um objeto (um retângulo de $40 \times 20$ pixels) num ponto de contato (40 × 120 pixels) em um monitor de computador. Ao praticante era permitida a escolha da velocidade (três velocidades possíveis) em que esse objeto se moveria, em cada tentativa. Após cada tentativa os participantes receberam uma informação sobre o seu desempenho na tarefa.

No primeiro experimento, cujo objetivo era investigar se as estratégias elaboradas pelos aprendizes, numa condição de prática autocontrolada, se modificam com o fornecimento de uma meta de aprendizagem. Para isso os participantes $(n=16)$ foram divididos em dois grupos experimentais: TAR $(n=8)$ que recebeu a meta da tarefa e TES $(n=8)$ que recebeu adicionalmente a meta de aprendizagem. Ambos puderam autocontrolar a prática e receberam a meta da tarefa "escolha a ordem das velocidades de forma a fazer o menor erro possível em todas as 90 tentativas". O TES recebeu a meta de aprendizagem "escolha a ordem das velocidades de forma a preparar-se para um teste, no qual você não poderá escolher a ordem das velocidades e essas virão se alternando" no início da prática. Para ambos os grupos, antes de cada tentativa, foi apresentando o número de tentativas que o indivíduo praticou em cada velocidade. Após cada tentativa os participantes receberam uma informação sobre o seu desempenho na tarefa. Ao final da fase de aquisição, ambos os grupos foram informados de que realizariam um teste. No teste de transferência imediato (TRi) os participantes não puderam escolher a ordem das velocidades e não receberam feedback, sendo que essas tiveram uma ordem pseudoaleatória - combinação de velocidades elaborada previamente pelo experimentador, de maneira que uma mesma velocidade não fosse repetida na tentativa subsequente. Foram, ao todo, 24 tentativas (3 velocidades, 8 vezes cada velocidade: 1, 2, 1, 3, 2, 3, 1, 2, 3, 2, 1, 3, 1, 2, 1, 3, 2, 3, $1,2,3,2,1,3)$. O teste de Tri foi idêntico para ambos os grupos e o teste de transferência atrasado (TRa) consistiu no mesmo teste (TRi), porém realizado 15 minutos após. Para o Experimento 1 foram propostas duas questões: (1) fornecer ao aprendiz uma meta de aprendizagem afeta as estratégias de aprendizagem elaboradas por ele? (2) A aprendizagem motora é favorecida por essas estratégias? 
Sobre a primeira questão o grupo que recebeu a instrução de se preparar para o teste (TES) apresentou comportamento que mostra a elaboração de estratégias diferentes em relação ao grupo que não recebeu esta informação, inferidos pelo maior número de variações durante a aquisição. Em resposta à segunda questão, as medidas de erro absoluto e variável permitiram concluir que as estratégias elaboradas pelos participantes do grupo TES proporcionaram efeitos benéficos para a aprendizagem. Bastos (2010) aponta como uma possível explicação para o efeito benéfico observado para o grupo TES, a possibilidade de a habilidade motora ter sido alocada de forma privilegiada na memória devido à intenção dos participantes do grupo TES de realizarem a tarefa em teste após a fase de aquisição. No entanto, esta hipótese não se sustenta, pois uma vez que houve a realização (fulfillment) da intenção, o efeito de superioridade desapareceria, o que não foi observado, dado que a vantagem do grupo TES sobre o grupo TAR se manteve no TRa. Assim, Bastos (2010) discorre acerca de duas ideias para explicar os resultados: a) o grupo TES realizou maior esforço cognitivo em comparação ao grupo TAR, tendo em vista que, para controlar a prática, levava em consideração não somente a meta da tarefa (caso do grupo TAR), mas também a preparação para o teste que deveriam realizar (meta da aprendizagem); b) a prática variada, realizada pelo grupo TES, independentemente do esforço cognitivo para lidar com os dois elementos citados em "a", poderia ter conduzido a um desempenho superior nos testes de transferência.

Considerando os resultados obtidos pelo experimento1 surgiu uma nova questão a ser investigada: a organização da prática resultante das escolhas realizadas pelos participantes no experimento 1 produziriam os mesmos efeitos na aprendizagem, sem a presença da instrução sobre o teste?

Um segundo experimento foi elaborado por Bastos (2010) almejando responder a esta questão. O experimento objetivou investigar se as estratégias de aprendizagem, traduzidas na forma como a prática foi organizada pelos participantes no experimento 1, produzem o mesmo efeito na aprendizagem, independentemente do fornecimento da meta de aprendizagem (BASTOS, 2010, p. 53).

Igualmente ao experimento 1, o experimento 2 consistiu das mesmas três etapas experimentais: a) fase de aquisição; b) teste de transferência imediato (TRi); c) teste de transferência atrasado (TRa). 
Foram organizados quatro grupos experimentais: a) TES (o mesmo descrito e analisado no experimento 1); b) TAR (o mesmo descrito e analisado no experimento 1); c) YOK (espelhado do grupo TES); d) YTA (espelhado do grupo TAR). YOK e YTA são grupos yoked (espelhados com os grupos autocontrolados) em que cada participante praticou, na fase de aquisição, a estrutura de prática resultante das escolhas feitas pelos participantes de TES e TAR. Ambos os grupos foram pareados por sexo com os seus respectivos grupos autocontrolados.

Os procedimentos foram os mesmos utilizados no experimento 1. Na fase de aquisição, os grupos YOK e YTA foram informados de que realizariam 90 tentativas da tarefa e que a velocidade de deslocamento do objeto na tela poderia variar em 3 velocidades. Cada velocidade foi apresentada uma vez durante a explicação da tarefa. Ambos os grupos yoked foram informados do TRi ao término da prática. $\mathrm{O}$ TRa foi realizado 15 minutos após o TRi. Foram utilizadas as mesmas medidas de desempenho do experimento 1. Os resultados permitiram concluir que a estrutura de prática, e não o esforço cognitivo envolvido, foi responsável pelos efeitos observados no experimento 1.

No presente estudo, o objetivo não foi investigar o efeito do autocontrole na aprendizagem, mas sim utilizar essa condição como procedimento que possibilite aos participantes a elaboração de estratégias, o que viabilizaria a investigação do efeito da meta de aprendizagem na aquisição da habilidade do Judô. Em outras palavras, fornecer ao aprendiz uma meta de aprendizagem afeta as estratégias de aprendizagem elaboradas por ele? Ainda, a aprendizagem motora é favorecida por essas estratégias? A meta da tarefa refere-se ao que o aprendiz deverá ser capaz de realizar para obter sucesso na tarefa motora, o golpe o soto gari. Já a meta de aprendizagem é o objetivo que o aprendiz busca alcançar com um conjunto de tentativas de prática, isto é, a sua aplicação durante o randori. A meta de aprendizagem refere-se ao contexto que é negligenciado no ensino do golpe por meio do uchi komi. Tendo a possibilidade de escolher entre as três formas de realizar o golpe na fase de aquisição, o estudo pretende investigar o efeito da meta de aprendizagem na aquisição do golpe o soto gari.

\section{OBJETIVO}


O objetivo do presente estudo é investigar o efeito da meta de aprendizagem na aquisição do golpe de Judô o soto gari.

\section{MÉTODO}

\subsection{Participantes}

A amostra foi composta por crianças 24 crianças voluntárias, do Colégio Aldeia dos Pandavas, localizado em São Paulo - SP, com idade média de 7,62 anos $(S D=0,97)$ sem experiência na prática do Judô. A participação no experimento foi condicionada ao preenchimento de um Termo de Consentimento (Anexo I) pelos pais ou responsáveis legais, sendo que neste foi informado os procedimentos da pesquisa, bem como os direitos do participante em um experimento para fins científicos. O estudo foi aprovado pelo Comitê de Ética da Escola de Educação Física e Esporte da Universidade de São Paulo, no dia 31/08/2018.

\subsection{Tarefa}

A tarefa constituiu na realização do golpe o soto gari que é um golpe tradicionalmente ensinado aos praticantes iniciantes, muitas vezes o primeiro. $O$ nome o soto gari é composto por três palavras de origem japonesa: $0=$ grande; soto = externo; gari = ceifar. O golpe envolve a execução dos seguintes componentes na fase do kuzushi: puxar com ambos os braços o uke para a diagonal anterior direita, ao mesmo tempo posicionar o pé esquerdo do lado exterior do pé direito do uke (1); puxar com a mão esquerda e ao mesmo tempo empurrar com a mão direita, objetivando provocar o desequilíbrio posterior direito (2). $\mathrm{Na}$ fase do tsukuri: avançar a perna esquerda (3); enroscar com a perna direita na perna direita do uke (4). Na fase do kake: puxar a perna direita do uke (5) e ao mesmo tempo puxar para baixo com a mão esquerda e empurrar com a mão direita para trás (6) (DAIGO, 2005; KANO, 1994; MIFUNE, 2004; SHINOHARA, 1982). Essa forma de execução é o padrão da técnica, ou seja, aquele previsto no kata. Para melhor descrever os componentes do o soto gari, foi elaborado um esquema em que se tem os 
componentes em cada fase do golpe. Trata-se dos movimentos realizados pelo tori em cada fase. Alguns componentes ocorrem de modo simultâneo, requisitando movimentos diferentes para atingir um objetivo em comum, por exemplo, movimentos diferentes entre os braços direto e esquerdo para conduzir o uke.

As três formas de execução do golpe a serem autocontroladas são as seguintes:

Primeira forma, o uchi komi tradicional (UK): (1) puxar com a mão esquerda na diagonal para frente o braço direito do uke, ao mesmo tempo empurrar com a mão direita a gola do uke; (2) avançar a perna esquerda; (3) enroscar com a perna direita na perna direita do uke; (4) retornar na posição inicial (Figura 3).

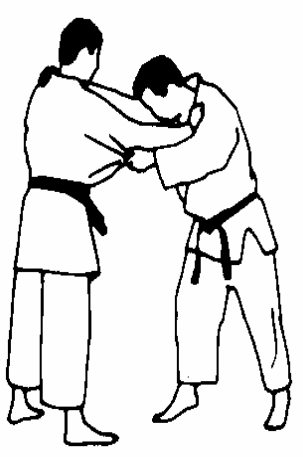

1

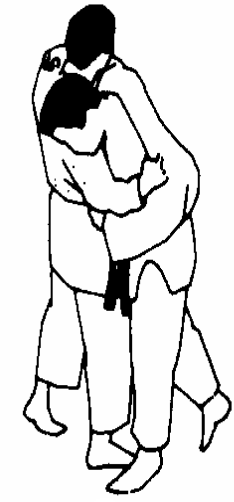

2

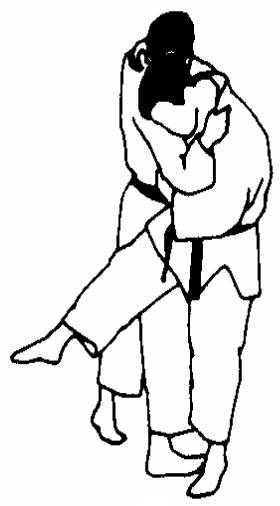

3

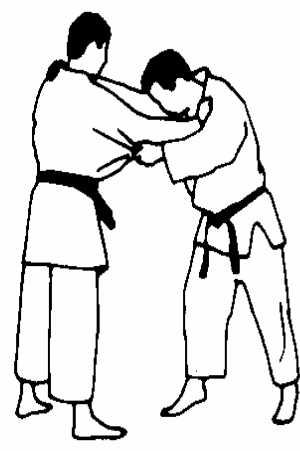

4

Figura 3 - Representação do uchi komi.

Segunda forma, o puxar pela manga (PM). Na fase do kuzushi : puxar a mão da manga (hikki te) na diagonal para frente em relação ao uke (1); no momento que o uke apoia seu corpo no pé direito, inverter a direção e empurrar na diagonal para trás do uke. Na fase do tsukuri: avançar a perna esquerda (3); enroscar com a perna direita na perna direita do uke (4). Na fase do kake: puxar a perna direita do uke (5) e ao mesmo tempo, puxar para baixo com a mão esquerda e empurrar com a mão direita para trás (6) (GOMES, 2016) (Figura 4).

Terceira forma, o puxar e empurrar (PE). Na fase do kuzushi: puxar a mão da gola (tsuri te) em sua própria direção aproximando o uke (1); ao resistir ao movimento, o uke apoia-se em sua perna esquerda; deslocar o peso do corpo para a perna direita (2). Na fase do tsukuri: avançar a perna esquerda (3); enroscar com a 
perna direita na perna direita do uke (4). $\mathrm{Na}$ fase do kake: puxar a perna direita do uke (5) e ao mesmo tempo, puxar para baixo com a mão esquerda e empurrar com a mão direita para trás (6) (GOMES, 2016) (Figura 5).

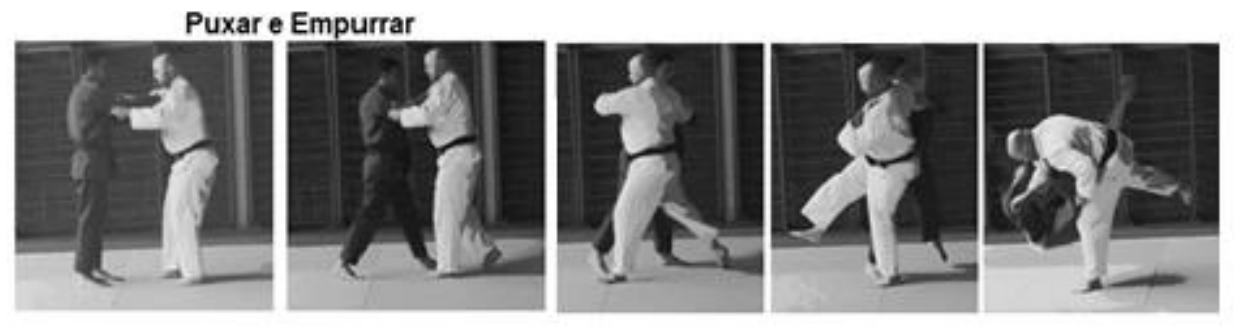

Figura 4 - Segunda forma do golpe o soto gari (adaptado de GOMES, 2016).
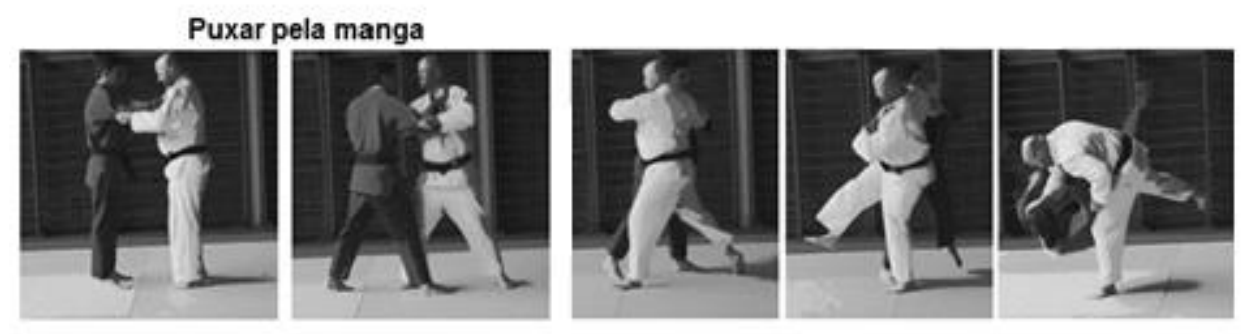

Figura 5 Terceira forma do golpe o soto gari (adaptado de GOMES, 2016).

Os participantes estavam trajados com judogi - vestimenta própria para a prática do Judô. Todas as sessões foram realizadas em um tatame com medidas de $6 \mathrm{~m} \times 6 \mathrm{~m}$. O vídeo foi projetado (Projetor Epson Powerlite S27 3LCD 2700 Lumens Wireless Ready) em uma tela de aproximadamente 1,80m (largura) x 1,20m (altura) suspensa entre $0,80 \mathrm{~m}$ e $1,00 \mathrm{~m}$ do solo, e a instrução verbal transmitida por caixas de som (Caixa de Som Bluetooth Portátil Preto GO JBL, 3W) ligadas a um notebook (Asus VivoBook S), distribuídas ao lado da tela. Para a filmagem foi utilizada uma câmera Go-Pro Sports posicionada na diagonal inferior esquerda. A câmera foi posta em um tripé na altura entre $0,80 \mathrm{~m}$ e $1,20 \mathrm{~m}$. Foi utilizado o software Kinovea para a análise das imagens.

\subsection{Delineamento experimental e procedimentos}

Para todos os grupos, o experimento consistiu de 4 etapas com sete sessões de prática (uma sessão por dia com duração de aproximadamente 25 minutos cada). 
As sessões ocorreram no intervalo de duas a três vezes por semana. Na primeira sessão foi ensinado o fundamento do rei-ho (cumprimento inicial), explicando por que e quando deve acontecer. Em seguida foi realizada a prática do ushiro ukemi (queda para trás). Ela se constituiu de 50 execuções, utilizando-se de um processo pedagógico com as seguintes características: nas dez primeiras execuções as crianças permaneceram "deitadas" (te uchi ukemi); da décima até a vigésima execução as crianças iniciaram a técnica a partir da posição sentada; já da vigésima à trigésima realizaram a partir da posição agachadas; e nas últimas vinte execuções realizaram a partir da posição em pé (Tabela 1). Foi dado o intervalo de 1 minuto entre os blocos.

\begin{tabular}{ll}
\hline Sessões do ushiro ukemi \\
\hline 10 bloco & Realização do te uchi ukemi (10 vezes) \\
\hline 20 bloco & Realização de 10 quedas a partir da posição sentada \\
3o bloco & Realização de 10 quedas a partir da posição agachada \\
4 ㅇ bloco & Realização de 20 quedas a partir da posição em pé \\
\hline
\end{tabular}

Tabela 1 - Sessões do ushiro ukemi

Ainda na primeira sessão, após a prática do ushiro ukemi foi realizado o préteste para a formação de grupos experimentais equivalentes. Neste teste o golpe 0 soto gari foi demonstrado duas vezes por meio de um vídeo e cada participante executou 3 tentativas. Para a análise do golpe foi utilizada a lista de checagem elaborada e validade por Gomes et al. (2002) (Anexo II).

Dois grupos foram formados considerando o desempenho médio nas três tentativas:

a) Grupo Meta Tarefa (GMT): 12 participantes, com média de idade de 7,75 anos $(S D=0,86)$, realizaram a prática com possibilidade de escolha das três formas do golpe a cada bloco de tentativas e recebeu a meta da tarefa no início de cada sessão de prática; a instrução fornecida para tal fim foi "você assistirá a três vídeos do golpe o soto gari que poderá praticar". 
b) Grupo Meta Aprendizagem (GMA): 12 participantes, com média de idade de 7,5 anos $(S D=0,87)$, realizaram a prática com possibilidade de escolha das três formas do golpe a cada bloco de tentativas e recebeu, além da meta da tarefa, a meta de aprendizagem no início de cada sessão de prática; a instrução fornecida para tal fim foi "você assistirá a três vídeos do golpe o soto gari que poderá praticar; no último dia de prática você irá realizar um teste - uma luta de 1 minuto e 30 segundos - em que tentará derrubar o adversário utilizando o golpe o soto gari'. Para garantir que todos compreendessem o significado de "luta", os integrantes do GMA assistiram a uma aula de Judô no Colégio, na qual foi mostrado o randori (luta). Para a compreensão do que se constituía o Teste de Transferência os integrantes do GMT assistiram ao Teste de Transferência do GMA.

Da segunda à sexta sessão de prática, no início e no final de cada uma, os participantes realizaram o fundamento rei-ho. Em cada uma das sessões foram executadas também vinte repetições de ushiro ukemi.

O experimento foi desenvolvido em quatro etapas: a) pré-teste - $1^{\text {aa }}$ sessão; b) fase de aquisição ( $A Q$ ), da segunda a sexta sessão, em que foram praticadas 250 tentativas (50 por sessão, dividida em 5 blocos de 10 tentativas, 2 minutos de descanso entre os blocos); c) TRi na sexta sessão, após as 50 tentativas de prática; d) TRa na sétima sessão, realizado 7 dias após o TRi. O TRi e o TRa consistiram-se do randori controlado que teve a duração de 1 minuto e 30 segundos em que o uke foi instruído para não resistir à movimentação do tori e não atacou. Foi utilizado o mesmo uke para ambos os grupos nos testes de transferência (Tabela 2). Todas as tentativas foram registradas e todos os testes foram filmados para avaliação posterior.

Para as sessões de prática foram apresentados para ambos os grupos três vídeos referentes às três formas de execução do golpe. O participante escolheria dentre as três formas uma a qual iria praticar durante as 10 tentativas. Cada vídeo contou com a demonstração do golpe e evidenciou os pontos essenciais, tais como a direção das mãos, a posição dos pés, a ação da varrida e a posição final da projeção. A cada dez tentativas os vídeos foram reapresentados e, dentre as três formas apresentadas uma era escolhida para a prática durante as dez tentativas, este processo foi repetido ao longo da sessão de prática. Em cada sessão de prática foi fornecido por meio de vídeo um total de 15 instruções (verbal e visual) de cada 
forma do golpe a aproximadamente $25 \%$ da velocidade real. Cada vídeo teve duração de 25 segundos, divididos em dois momentos: nos primeiros dez segundos foram apresentados os golpes com instrução visual na tela, aparecendo o nome da forma; os quinze segundos restantes foram destinados às instruções específicas sobre a execução dos golpes.

A prática foi realizada com três ou quatro duplas (praticante e o uke), de ambos os grupos experimentais. Antes da prática e após a exibição dos vídeos era perguntando ao praticante qual forma de treinamento foi escolhida. As escolhas foram registradas.

\begin{tabular}{ll}
\hline Sessões do experimento & PRÉ- TESTE \\
\hline $1^{\text {a }}$ sessão & $A Q-5$ blocos de 10 tentativas \\
$2^{\text {a }}$ sessão & $A Q-5$ blocos de 10 tentativas \\
$3^{\text {a }}$ sessão & $A Q-5$ blocos de 10 tentativas \\
$4^{\text {a }}$ sessão & $A Q-5$ blocos de 10 tentativas \\
$5^{\text {a }}$ sessão & $A Q-5$ blocos de 10 tentativas + TRi \\
$6^{\text {a }}$ sessão & $T R a$ \\
$7^{\text {a }}$ sessão
\end{tabular}

Tabela 2 - Sessões do experimento.

\subsection{Medidas}

Os testes de transferência tiveram a duração de 1 minuto e 30 segundos e a avaliação do desempenho foi feita com base nas seguintes medidas:

a) Número de tentativas de execução da técnica: foram contabilizadas as tentativas realizadas pelo praticante. Entende-se por tentativa a ação de posicionar a perna direita na perna direita do uke, movimento característico do o soto gari, sem projeção; 
b) Sucesso na execução da técnica: uma técnica foi considerada bemsucedida quando contemplassem os critérios estabelecidos pela Federação Internacional de Judô sobre a avaliação e pontuação de técnica de o soto gari:

a. Ippon (10 pontos): foi considerado ippon quando a técnica for realizada com força, domínio, projetando o oponente completamente de costas e em velocidade;

b. Wazari (5 pontos): foi considerado wazari quando a técnica realizada não contemplasse um dos quesitos previstos para o ippon.

c. Yuko (3 pontos): foi considerado yuko quando a técnica realizada não contemplasse dois dos quesitos previstos para o ippon;

d.Koka (1 ponto): foi considerado koka quando a técnica realizada não contemplasse três dos quesitos previstos para o ippon;

e.Não realização da projeção (0 ponto).

Segundo as regras atuais de arbitragem (FIJ 2018), as pontuações koka e yuko foram incorporadas ao wazari, mas no presente estudo estas pontuações foram mantidas para maior detalhamento na avaliação das projeções. Dois wazaris não foram convertidos em ippon.

\subsubsection{Teste de fidedignidade:}

Foram realizados testes de fidedignidade para medir a consistência e reprodutividade das medidas estabelecidas. Para tanto, dois avaliadores especialistas em Judô e árbitros analisaram 10 vídeos do Teste de Transferência Imediato, 5 de cada grupo, uma primeira análise foi realizada (teste) e após uma semana os mesmo vídeos foram analisados (reteste). Foi utilizado o Teste de Fidedignidade de Concordância entre Observadores (CEO), proposto por Thomas, Nelson e Silverman (2012), cuja fórmula: CEO $=\frac{\text { CONCORDÂNCIA }}{(\text { CONCORDÂNCIA+DISCORDÂNCIA) }}$

Os valores poderão de CEO podem variar de 0 a 1, sendo 1 igual a 100\%. Há uma variação de erro entre o teste-reteste atribuída para alguns itens: a) amostragem de conteúdo, que no caso são a quantidade de tentativas do golpe e, em caso de êxito a pontuação obtida, podendo variar até $20 \%$; b) amostragem de conteúdo e tempo, ou seja, um mesmo avaliador pode após uma semana pode variar sua avaliação em até $10 \%$; c) diferença entre avaliadores de $8 \%$. Portanto 
valores encontrados maiores que $62 \%$ podem ser validados (ANASTASI; URBINA, 2000 apud GOMES 2007).

Os valores descritos na Tabela 3 podem ser considerados aceitáveis porque todos os valores estão acima de $70 \%$.

\begin{tabular}{|l|c|c|}
\cline { 2 - 3 } \multicolumn{1}{c|}{} & \multicolumn{2}{c|}{ Resultado do CEO } \\
\cline { 2 - 3 } \multicolumn{1}{c|}{} & Pontuação & no de Tentativas \\
\hline Avaliador 1 & $90 \%$ & $70 \%$ \\
\hline Avaliador 2 & $80 \%$ & $80 \%$ \\
\hline
\end{tabular}

Tabela 3 - CEO obtido das medidas: pontuação obtida em caso de projeção e a quantidade de tentativas do golpe o soto gari.

Foi calculado o coeficiente de correlação de Pearson, comparando os valores encontrados entre os Avaliadores para cada medida. Os valores encontrados foram: a) para a medida pontuação $p=0,83$; b) para a medida número de tentativas $p^{\prime}=0,97$. Como os valores encontrados estão próximo de 1 há uma associação positiva e bastante forte entre os valores encontrados.

Considerou-se, portanto, que o instrumento de avaliação é fidedigno, uma vez que se apresentou consistente e reprodutível de acordo com os avaliadores.

\subsection{Análise estatística}

Para a escolha dos testes adequados foi realizado o teste de normalidade de Shapiro-Wilk para todas as variáveis analisadas, mas não foi encontrada essa normalidade. Desta maneira, para a análise inferencial intergrupos, as pontuações obtidas nos testes de transferência foram tratadas utilizando o teste não paramétrico de Mann-Whitney, pois os dados de desempenho são de natureza ordinal. Para a análise intragrupo foi utilizado o Teste de Wilcoxon, buscando verificar a existência de diferenças significativas. Todos os procedimentos estatísticos foram realizados no pacote IBM SPSS 24.0 e adotado um nível de significância de 5\%.

Quanto às escolhas das formas de golpe por cada participante, foi elaborada uma análise descritiva com as frequências de escolha. Para o cálculo médio de 
variações realizadas pelo grupo, foram analisadas quantas vezes o praticante variou na escolha das formas em cada uma das 5 sessões, portanto, os valores variaram de 0 (não variou) a 4 (variou em todos blocos).

Para a análise da configuração total do golpe, utilizou-se a soma dos escores das três tentativas, portanto as notas variaram de 6 a 24 pontos.

\section{RESULTADOS}

Para garantir que os dois grupos iniciaram a prática no mesmo nível de desempenho, as pontuações obtidas no pré-teste foram comparadas utilizando-se o teste $U$ de Mann-Whitney. $O$ resultado $(U=46,00 ; p>0,05)$ mostrou que não havia diferença entre os grupos, evidenciando a homogeneidade dos grupos.

\subsection{Número de tentativas de execução da técnica}

A análise estatística intergrupos detectou diferença entre os grupos tanto no TRi (Gráfico 1) quanto no TRa (Gráfico 2), respectivamente: ( $U=27,00 ; p<0,05)$ e $(U=28,00 ; p<0,005)$. No TRi, quanto ao posto médio (pm) e a soma dos postos (sm), os resultados foram para o GMA (pm $=16,25$; $\mathrm{sm}=195,00)$ e para $\circ \mathrm{GMT}$ (pm = $8,75 ; \mathrm{sm}=105,00)$. No TRa, os valores encontrados foram: GMA ( $\mathrm{pm}=16,17$; $\mathrm{sm}=194,00)$ e GMT (pm=8,83; sm=106,00).

\subsection{Sucesso na execução da técnica}

A análise estatística intergrupos não identificou diferença entre os grupos tanto no TRi quanto no TRa, respectivamente: $(U=52,00 ; p>0,05)$ e $(U=45,00$; $p>0,05)$.

\subsection{Variação na escolha das formas de golpe}

Quanto a variação na escolha das formas de golpes por bloco de tentativas não foram encontradas diferenças significativas entre a quantidade de variações que os grupos realizaram $(U=61,50 ; p>0,05)$. 
Analisando-se a frequência nas escolhas das formas de golpe, observou-se que o GMA escolheu mais vezes o PE, ao passo que o GMT escolheu mais o PM (Gráficos 3). O GMA favoreceu as formas que tinham projeção no final (PE e PM), enquanto GMT não apresentou este comportamento.

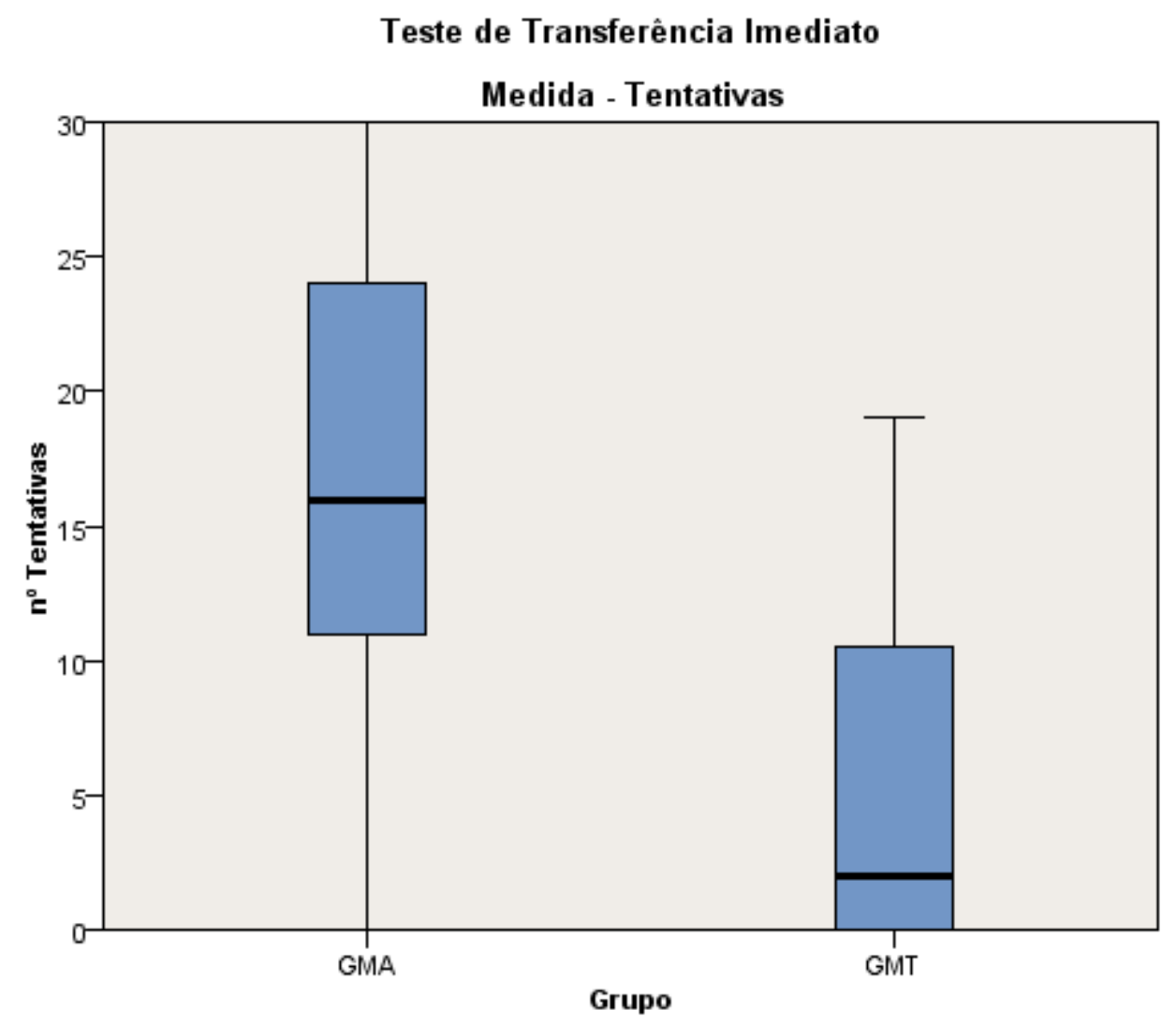

Comparação entre os Grupos - GMA e GMT

Gráfico 1 - Teste de Transferência Imediato - Medida Número de Tentativas 


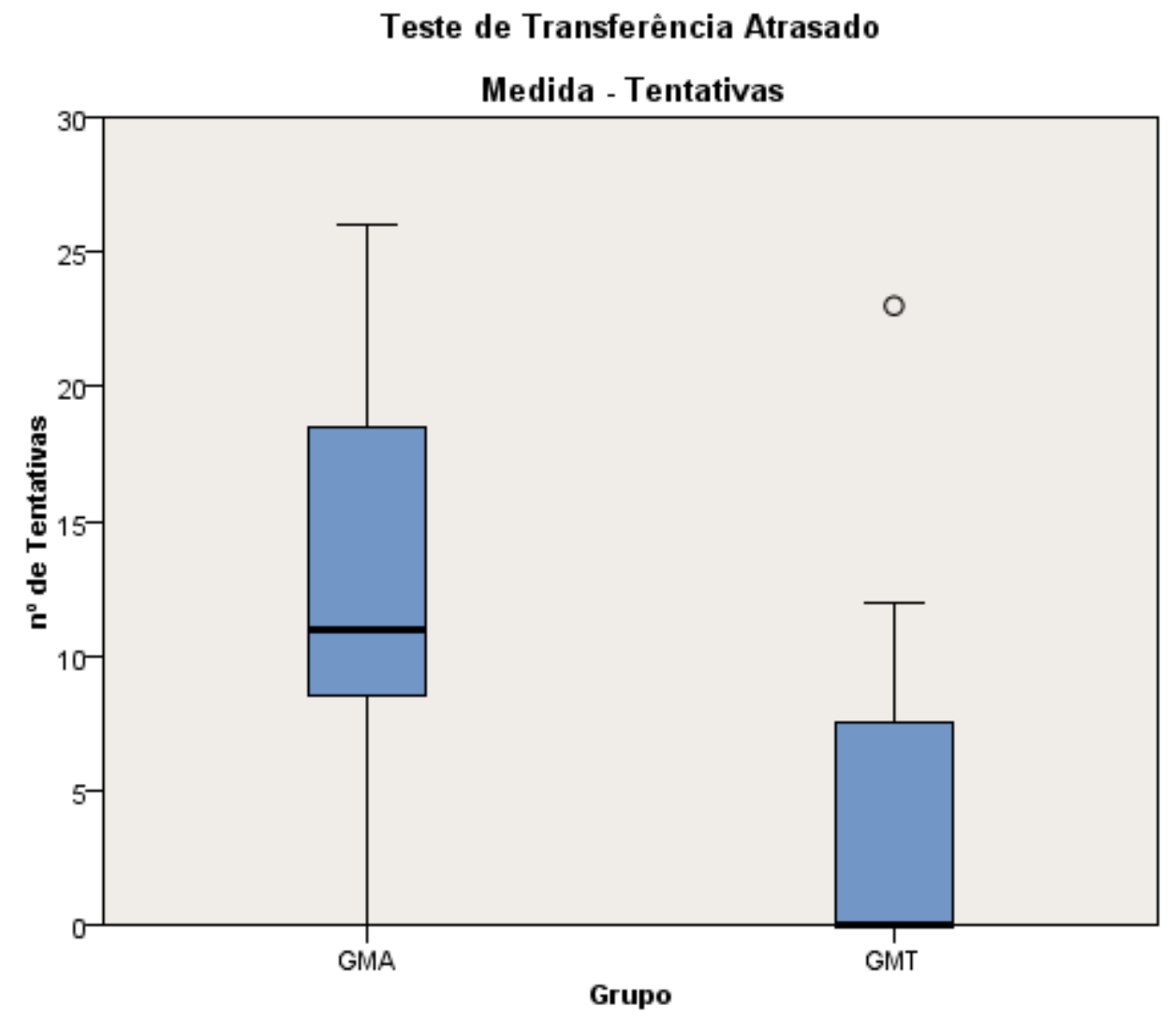

Comparação entre os Grupos - GMA e GMT

Gráfico 2 - Teste de Transferência Atrasado - Medida número de Tentativas. 


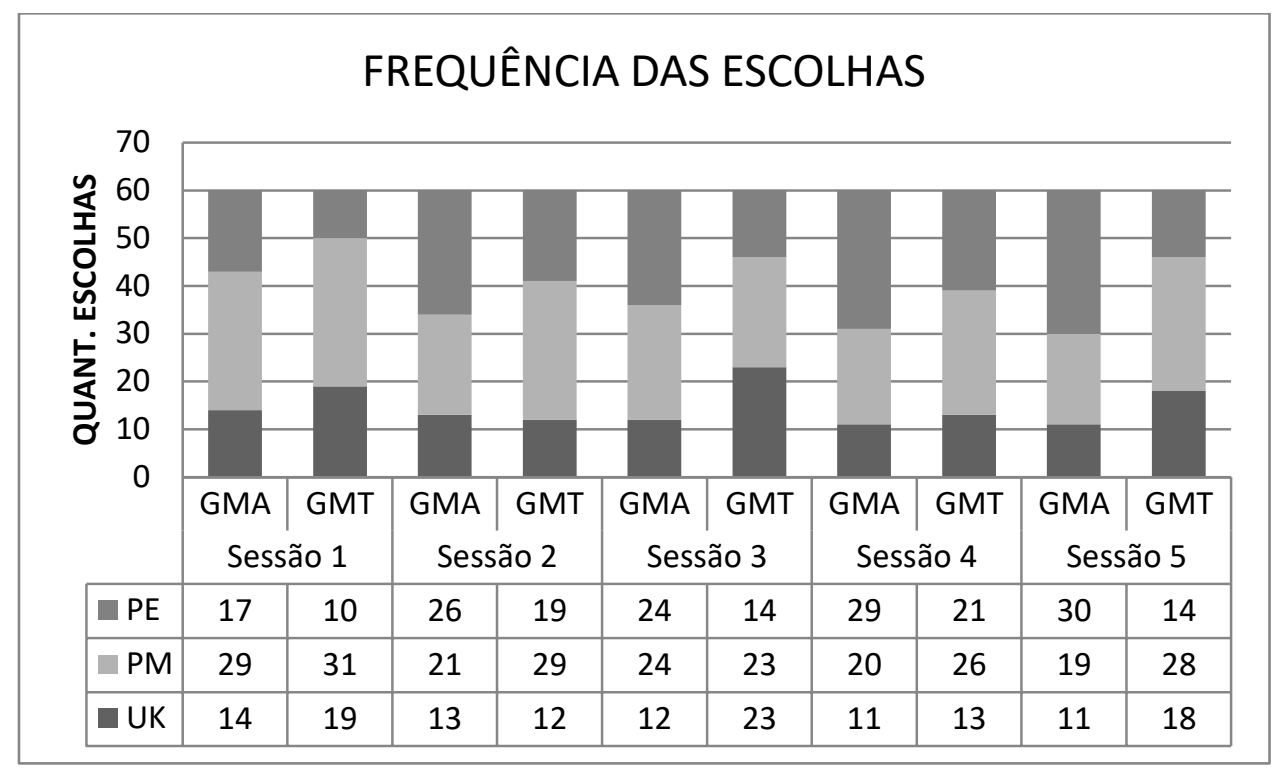

Gráfico 3 - Frequência de escolhas das formas.

Os valores representam a quantidade que cada forma foi escolhida durante as sessões.

\subsection{Desempenho intragrupo nos testes de transferência}

Foi observado melhora significativa na medida sucesso na execução da técnica (b) do grupo GMA ( $Z=-2,091$; $p<0,05)$ (Gráfico 4) no TRi $(Q 2=1,0$ e $\| Q=5,75)$ e no TRa $(Q 2=10,0$ e $I I Q=33,0)$, mas o mesmo não foi observado no $G M T(Z=-$ 0,813; p>0,05)(Gráfico 4). Na medida número de tentativas de execução da técnica (a) não foram encontradas diferenças significativas entre o TRi e TRa para ambos os grupos: GMA $(Z=-1,158 ; p>0,05)$ e GMT $(Z=-1,611 ; p>0,05)$. 


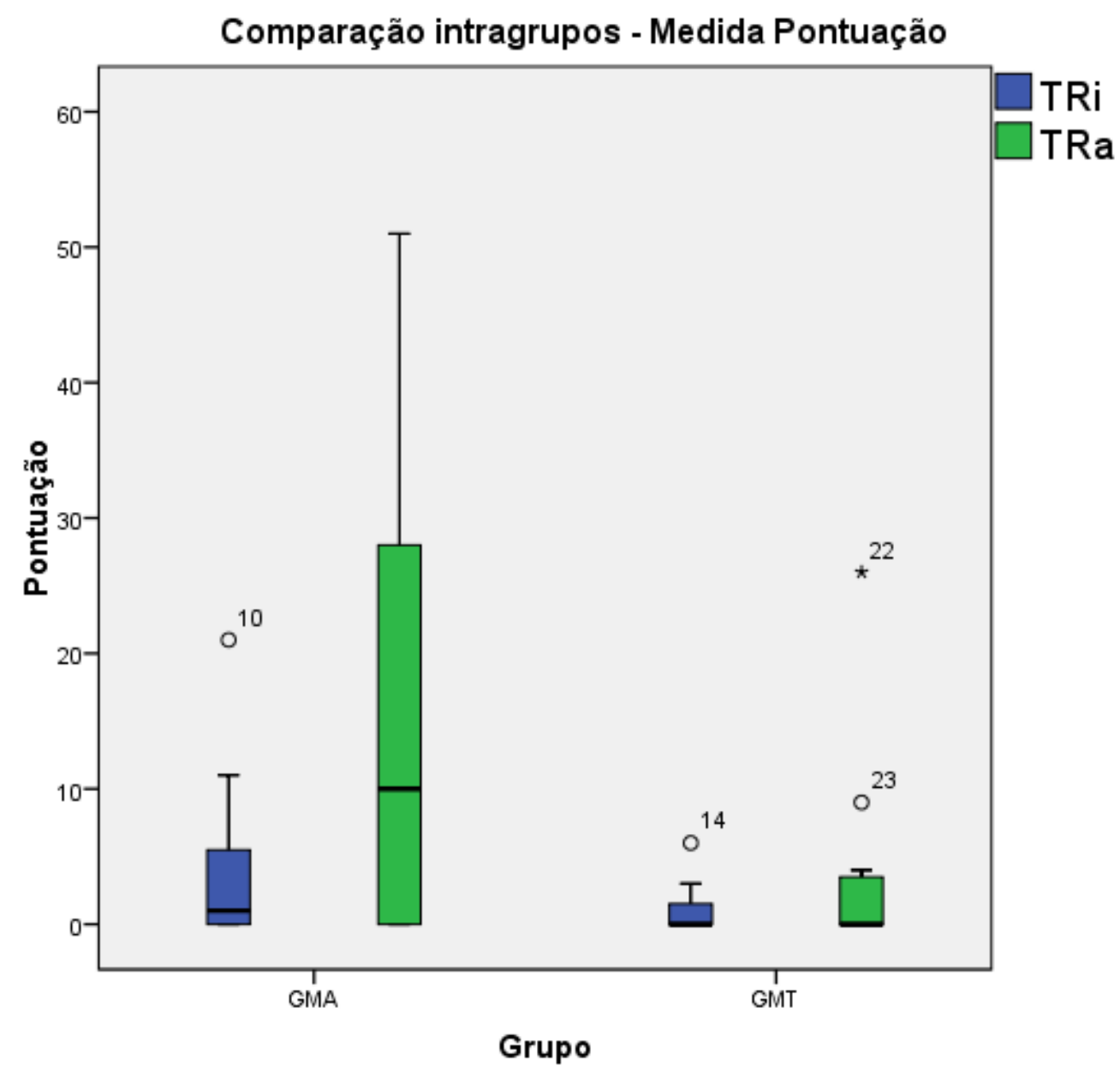

Gráfico 4 - Comparação dos Testes de Transferências Imediato e Atrasado Medida Pontuação.

\section{DISCUSSÃO}

Uma luta de Judô tem característica dual: os lutadores tentam derrubar um ao outro, de maneira que o ambiente se encontra em constante mudança para ambos (GOMES, 2007). A cada momento, o lutador tenta criar uma situação para projetar o oponente ao solo e ao mesmo tempo não ser projetado. Para o sucesso do golpe é necessário diversos fatores como o desequilíbrio, posicionamento e encaixe, além da própria capacidade de detectar o momento exato para execução do movimento (GOMES; PEROTTI Jr.; TANI, 2016). 
A característica dual do Judô expressa o contexto alvo no qual o golpe será executado. O contexto alvo pode ser definido como o quadro ambiental no qual uma pessoa deseja ser capaz de realizar uma habilidade (SCHMIDT; LEE, 2016). Isto significa que as técnicas do Judô necessitam ser ajustadas em resposta às situações inesperadas provocadas pelo oponente. Desta forma, no processo de aquisição destas habilidades torna-se de fundamental importância a integração dos mecanismos perceptivos e decisórios. Ao analisar o método tradicional de ensino dos golpes, por meio do uchi komi, percebe-se que ele não mantém relação com o contexto alvo (GOMES; PEROTTI Jr.; TANI, 2016).

Outra característica que está intimamente relacionada com o sucesso da execução da técnica é a composição do golpe em três fases sequenciais e interdependentes (kuzushi, tsukuri e kake), em que cada fase contempla ações necessárias para a realização da técnica (TAGUSARI; DOS SANTOS; TANI, 2016). Gomes (2016) ressalta que o kuzushi não implica apenas a execução do movimento de desequilibrar o oponente (ação motora do kuzushi), mas assegurar que ele fique de fato em situação de desequilíbrio (efeito do kuzushi). Em um contexto de luta, deixar o oponente efetivamente desequilibrado pode ser logrado por meio de movimentos específicos, ou seja, os deslocamentos pré-kuzushi (GOMES, 2007).

Buscando aproximar a prática do golpe do Judô do contexto no qual a técnica será utilizada, o objetivo do presente estudo foi investigar o efeito do fornecimento da meta de aprendizagem na aprendizagem do golpe o soto gari. Para que pudesse verificar o efeito foram comparados dois grupos: a) GMA, que recebeu a meta da tarefa mais a informação que este golpe será utilizado em uma situação de randori; b) GMT que recebeu apenas a meta da tarefa.

Para a prática foram demonstradas três formas diferentes de execução do golpe o soto gari: duas possuíam a fase do kake, ou seja, culminavam na projeção do oponente, com a diferença na movimentação inicial para provocar o kuzushi; a terceira forma era a prática do uchi komi. Os participantes puderam escolher livremente quais destas formas iriam praticar.

Considerando primeiramente a elaboração de estratégias na fase de aquisição, o GMA, por saber que ao final da prática haveria um teste - um randori apresentou comportamentos que denotam a elaboração de estratégias diferenciadas em relação ao GMT. Estes comportamentos foram inferidos pela ênfase do GMA na 
escolha das formas que terminavam em projeção, ou seja, PM e PE, totalizando $79,6 \%$ de suas escolhas nos 5 blocos de tentativas, com predominância do PE $(42,00 \%)$. O UK foi a terceira opção em frequência em todos os blocos. O mesmo padrão não foi observado no GMT que apresentou escolhas sem um padrão definido entre as três formas de golpe.

No tocante aos efeitos na aprendizagem - quantidade de tentativas e pontuação obtida - ao comparar os grupos GMA e GMT nos testes de transferência, obteve-se diferença tanto no TRi quanto no TRa. O efeito da superioridade do GMA pode estar relacionada com estrutura de prática que, de maneira análoga, corrobora parcialmente o resultado do experimento 2 de Bastos (2010). Parcialmente no sentido de que não é possível descartar a hipótese do esforço cognitivo, mas no presente estudo os grupos não foram submetidos a uma análise comparativa com seus correspondentes espelhados.

Outro estudo que pode reforçar a argumentação do efeito da estrutura de prática foi conduzido por Gomes (2007) que investigou, em dois experimentos, métodos de ensino dos golpes de Judô, comparando a prática tradicional em diferentes contextos ambientais (estático e em movimento) com práticas que envolvem um deslocamento específico para gerar o kuzushi. Foram utilizados a prática do todo e a prática por partes progressivas para a aprendizagem dos golpes o soto gari e tai otoshi. Os resultados mostraram que a condição de prática do todo, cujas características são mais próximas à da luta, proporcionou desempenhos superiores no teste final e de retenção. Na conclusão Gomes (2007) aponta que as práticas tradicionais ou estáticas contemplaram só a forma do movimento, não provocando uma situação de desequilíbrio no adversário, consequentemente prejudicando a realização do golpe.

Na comparação da medida pontuação entre os grupos não foram encontradas diferenças significativas nos Testes de Transferências. Analisando a característica da medida "número de tentativas" com a pontuação obtida, tem-se em relação a primeira a apresentação de alguns componentes do golpe o soto gari (exceto a fase do kake) e na segunda a qualidade da técnica executada (contempla o kake). O fato de que os participantes não tinham nenhuma experiência com a tarefa (o soto gari), e não possuíam conhecimento dos fundamentos básicos do Judô como shinsei (postura), shintai (formas de andar no tatame), tai sabaki (movimentação do corpo) e 
kumi kata (forma de segurar no judogi) interferiu tanto na quantidade quanto na qualidade das projeções, o que justifica ambos os grupos não serem diferentes na medida Pontuação. O o soto gari é uma habilidade que possui diversos componentes que devem ser realizados em uma sequência, sob pena de comprometer a eficiência da técnica.

No que se refere a aprendizagem motora, pode-se afirmar que sujeitos em ambos os grupos estavam em estágios inicias de aprendizagem, nos quais em que predomina um número elevado de erros grosseiros e alta variabilidade durante as tentativas (FITTS e POSNER, 1967; apud GOMES, 2007). Durante as sessões de prática e testes de transferência não foram fornecidos feedbacks sobre a execução dos movimentos. Desta maneira, foi comum durante o teste a utilização da perna esquerda caracterizando outros golpes (ko soto gari e ko soto gake), ou foi realizado 0 ataque entre as pernas do uke caracterizando o o uchi gari e ko uchi gari. Geralmente isto é ocasionado pelo assincronismo entre a ação de desequilibrar e posicionar.

O GMA apresentou melhora na medida "b" (pontuação) em comparação entre TRi e TRa. Uma possível explicação para esta diferença pode estar no efeito da fadiga. Considerando que o TRi ocorreu logo após uma sessão composta por 50 tentativas do golpe pode ter ocasionado fadiga nos participantes. A fadiga é um efeito temporário que desaparece com o tempo (SCHMIDT; LEE, 2016). Isto justificaria o fato do GMA melhorar seu desempenho no TRa.

\section{CONCLUSÕES}

Pode-se afirmar que os efeitos produzidos pelo fornecimento da meta de aprendizagem na aprendizagem do golpe o soto gari são: a) a elaboração de estratégia para a escolha das formas do golpe, preferindo aquelas que representam o golpe completo; b) maior quantidade de tentativas do golpe nos testes de transferência; c) melhora no desempenho (pontuação) no TRa, apesar deste efeito carecer de investigação mais aprofundada.

Os resultados do presente trabalho oferecem indícios para questionar a utilização do uchi komi na aprendizagem das técnicas de Judô, pois os resultados encontrados apontam que, uma vez ofertada para o praticante a liberdade de escolha da forma na qual se pode praticar o golpe e informar que o golpe a ser 
praticado será utilizado em um contexto de randori (luta), os praticantes predominantemente optam por escolher as formas que envolvem a projeção.

Ainda são poucos os estudos voltados para o processo ensino-aprendizagem das técnicas do Judô. A área de investigação da Aprendizagem Motora oferece subsídios para que sejam realizados mais estudos para aprimorar o ensino destas técnicas.

\section{REFERÊNCIAS}

BASTOS, F.H. Efeito da meta de aprendizagem na aprendizagem autrocontrolada. 2010 Tese de Doutorado, Universidade de São Paulo, São Paulo, 2010.

BULL, W.J. Aikido - O caminho da sabedoria - a técnica. Editora Pensamento, 2005.

DAIGO, T. Kodokan Judo - throwing techniques. Tokyo: Kodansha International, 2005.

DUARTE, P. Princípios metodológicos do Judô - movimentos básicos, fundamentos e conduta. Global Sports Editora, 2015.

FIJ - Federação Internacional de Judô. Detailed Explanation of the IJF Judo Refereeing Rules. 2018. Disponível em: https://www.ijf.org/ijf/documents/, acesso em 02/10/2018.

FPJ - Federação Paulista de Judô. Apostila de história e filosofia do Judô. São Paulo, 2014.

FUKUDA, K. Born for the mat: a Kodokan kata textbook for womens, Judô.

Universidade da Califórinia, 1973.

- Ju no kata: a Kodokan textbook - Revisded and explanded from "Born for the mat". Berkeley: North Atlantic Books, 2003.

GALLAHUE, D.L.; OZMUN, J.C.; GOODWAY, J.D. Compreendendo o desenvolvimento motor: bebês, crianças, adolescentes e adultos. $7^{\text {a }}$ Edição. Porto Alegre: AMGH Editora Ltda, 2013.

GOMES, F.R.F. Aprendizagem do kuzushi (desequilíbrio) nos golpes de Judô o osoto gari e tai otoshi. 2007, Dissertação de Mestrado. Universidade de São Paulo, São Paulo.

GOMES, F.R.F. Estrutura de prática na aprendizagem do golpe de Judô o soto gari:

foco no kuzushi, 2016, Tese de Doutorado Universidade de São Paulo, São Paulo 2016. 
GOMES, F.R.F.; PEROTTI Jr., A.; TANI, G. Aprendizagem motora e o esnino do judô. In: TANI, G.; CORREAA, U.C. (Orgs.). Aprendizagem motora e o ensino do esporte. Blucher, São Paulo, 2016.

GOMES, F.R.F. et al. Golpe de judô o soto gari: validação de lista de checagem. Revista Brasileira de Ciência e Movimento, v. 17, n. 4, p. 1-9, 2010.

JONES, L. Kuzushi, tsukuri and kake in Kodokan Judo. The Kano Society Bulletin, v. 38, p. 1-5., 2018.

KANO, J. Kodokan Judo. Tokyo: Kodansha International, 1994. 2005.

Mind over muscle - Writings from the founder of Judô. Tokyo: Kodansha International,

MAGILL, R.A. Aprendizagem motora: conceitos e aplicações. Edgard Blücher, 2000.

MIFUNE, K. The canon of Judo - Classic teaching on principles and techniques. Tokyo: Kodansha International, 2004.

NUNES, A.V.; RUBIO, K.. As origens do judô brasileiro: a árvore genealógica dos medalhistas olímpicos. Revista Brasileira de Educação Física e Esporte, v. 26, n. 4, p. 667-678, 2012.

OTAKI, T.; DRAEGER D. F. Judo formal techniques: a complete guide to Kodokan randori no kata. Tóquio: Charles E. Turtle Company, 1990.

SANLI, E. A., et al. Understanding self-controlled motor learning protocols through the selfdetermination theory. Frontiers in Psychology, v. 3, p. 611, 2013.

SCHMIDT, R.A.; WRISBERG, D.F.. Aprendizagem e performance motora - Uma abordagem da aprendizagem baseada no problema. Porto Alegre: Artmed Editora, 2001.

SCHMIDT, R.A.; LEE. D.F.Motor control and learning - A behovioral emphasis. Champaing: Human Kinetics, 2005.

SHINOHARA, M. Manual de Judô Vila Sônia. São Paulo: produção independente, 1982.

TAGUSARI, F.I.; DOS SANTOS, F.G.; TANI, G.. Análise da complexidade das técnicas de te waza do Judô pertencentes ao gokyo. Journal of Physical Education, v. 27, 2016.

TAKAHASHI, M.; Mastering Judo. Human Kinetics, 2005.

TANI, G. Cinesiologia, educação física e esporte: ordem emanente do caos na estrutura acadêmica. Motus corporis, v. 3, n. 2, p. 9-50, 1996.

Processo adaptativo: uma concepção de aprendizagem motora além da estabilização. In: TANI, G. (Ed.) Comportamento motor: aprendizagem e desenvolvimento. Rio de Janeiro: Guanabara Koogan, p. 60-70, 2005.

Comportamento motor e sua relação com a educação física. Brazilian Journal of Motor Behavior, v. 1, n. 1, p. 20-31, 2006. 
TEIXEIRA, L.A. Controle Motor. Editora Manole, 2006.

THOMAS, J.R; NELSON, J.K; SILVERMAN, S.J Métodos de Pesquisa Em Atividade Física. 6르. ARTMED, 2012.

WATANABE, J.; AVAKIAN, L. The secrets of Judo: a text for instructors and students. 9 Ed. Rutland: Tuttle, 1997.

WATSON, B.N. Memórias de Jigoro Kano - O início da história do Judô. Editora Cultrix, 2011.

WULF, G. Attention and motor skill learning. Champaign, Illinois: Human Kinetics, 2007. 


\section{Anexo 1 - Termo de consentimento livre e esclarecido}

TERMO DE CONSENTIMENTO LIVRE E ESCLARECIDO

\section{I - DADOS DE IDENTIFICAÇÃO DO SUJEITO DA PESQUISA OU RESPONSÁVEL LEGAL}

\section{DADOS DO INDIVÍDUO}

Nome completo

Sexo

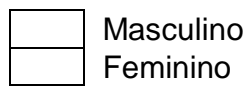

$R G$

Data de nascimento

Endereço completo

CEP

Fone

e-mail

\section{RESPONSÁVEL LEGAL}

Nome completo

Natureza (grau de parentesco, tutor, curador, etc.)

\begin{tabular}{l|l} 
Sexo & Masculino \\
& Feminino
\end{tabular}

RG

Data de nascimento

Endereço completo

CEP

Fone

e-mail

\section{II - DADOS SOBRE A PESQUISA CIENTÍFICA}

1. Título do Projeto de Pesquisa EFEITO DA META DE APRENDIZAGEM NA AQUISIÇÃO DO GOLPE DE JUDÔ O SOTO GARI

2. Pesquisador Responsável

Prof. Dr. Go Tani - Orientador

3. Cargo/Função

Professor Titular da Escola de Educação Física e Esporte da Universidade de São Paulo (USP)

4. Avaliação do risco da pesquisa:
$\square$ RISCO MÍNIMO $x$ RISCO BAIXO
$\square$ RISCO MÉDIO
$\square$ RISCO MAIOR

(probabilidade de que o indivíduo sofra algum dano como conseqüência imediata ou tardia do estudo)

\section{Duração da Pesquisa}

A pesquisa terá 7 sessões de prática com duração média de três semanas

III - EXPLICAÇÕES DO PESQUISADOR AO INDIVÍDUO OU SEU REPRESENTANTE LEGAL SOBRE A PESQUISA, DE FORMA CLARA E SIMPLES, CONSIGNANDO:

1. Seu (sua) filho (a) participará de um processo de aprendizagem do golpe de Judô o soto gari. Esse golpe é ensinado normalmente na iniciação da modalidade Judô. Esse estudo está focado no efeito do oferecimento de diferentes tipos de metas, e pretende investigar sua aprendizagem no golpe de Judô o soto gari. 
2. Inicialmente seu (sua) filho(a) participará em um dos dois grupos: Grupo Meta Tarefa (GMT) realizará a prática com possibilidade de escolha da $1^{\underline{a}}, 2^{\underline{a}}$ e $3^{\underline{a}}$ forma do golpe a cada tentativa e receberá a meta da tarefa no início de cada sessão de prática. Grupo Meta Aprendizagem (GMA) realizará a prática com possibilidade de escolha da $1^{\underline{a}}, 2^{\underline{a}}$ e $3^{a}$ forma do golpe a cada tentativa e receberá além da meta da tarefa a meta de aprendizagem no início de cada sessão de prática.

3. O projeto compreenderá quatro fases: pré-teste, aquisição, teste de transferência imediata e teste de transferência atrasada. Os movimentos serão filmados nos testes.

4. É importante ressaltar que o golpe de Judô "o soto gari" oferece riscos mínimo aos participantes, pois é o primeiro golpe de judô a ser aprendido durante a iniciação, e antes de cada aula as crianças aprenderão o amortecimento de queda específico chamado de "ushiro ukemi", para minimizar qualquer tipo de risco.

5. Ao participar deste experimento seu filho (a) aprenderá novas habilidades, que ampliarão o seu vocabulário motor, dessa forma tendo um propósito similar a disciplina de Educação Física nessa mesma faixa etária.

6. Os procedimentos experimentais são próximos de uma aula que acontece no dia-a-dia do Judô, assim a seu filho (a) terá a oportunidade de experimentar uma nova prática esportiva.

\section{IV - ESCLARECIMENTOS DADOS PELO PESQUISADOR SOBRE GARANTIAS DO SUJEITO DA PESQUISA:}

1. Você e seu (sua) filho (a) podem, em qualquer momento ter a informação que desejarem a respeito de procedimentos, eventuais riscos e benefícios relacionados à pesquisa;

2. Você e seu (sua) filho (a) têm a liberdade de retirar seu consentimento a qualquer momento e deixar de participar do estudo, sem que isto traga prejuízo;

3. Nenhuma informação a respeito da identidade do sei (sua) filho (a) ou do responsável (você) serão tornadas pública;

4. Será providenciada assistência por eventuais danos a saúde, decorrentes da pesquisa - HU (Hospital Universitário - USP).

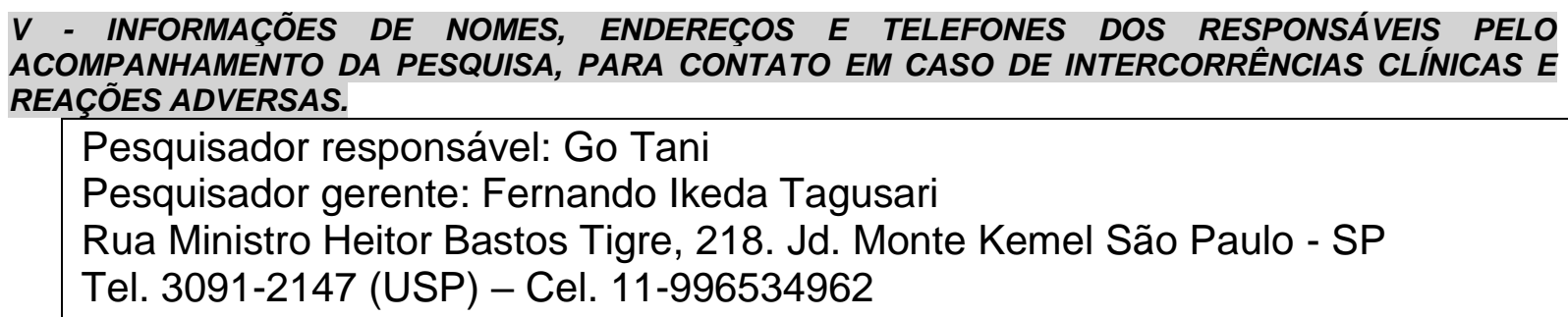

\section{VI. - OBSERVAÇ̃̃ES COMPLEMENTARES}

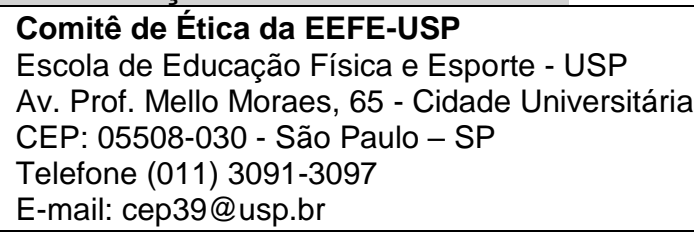

\section{VII - CONSENTIMENTO PÓS-ESCLARECIDO}

Declaro que, após convenientemente esclarecido pelo pesquisador e ter entendido o que me foi explicado, consinto em participar do presente Projeto de Pesquisa.

São Paulo, 


\section{Anexo 2 - Parecer consubstanciado do CEP}

\section{USP - ESCOLA DE EDUCAÇÃO FÍSICA E ESPORTE DA UNIVERSIDADE DE SÃO}

\section{PARECER CONSUBSTANCIADO DO CEP}

\section{DADOS DO PROJETO DE PESQUISA}

Título da Pesquisa: EFEITO DA META DE APRENDIZAGEM NA AQUISIÇÃO DO GOLPE DE JUDÔ O SOTO GARI

Pesquisador: Go Tani

Área Temática:

Versão: 1

CAAE: 92335518.0 .0000 .5391

Instituição Proponente: UNIVERSIDADE DE SAO PAULO

Patrocinador Principal: Financiamento Próprio

\section{DADOS DO PARECER}

Número do Parecer: 2.865 .152

Apresentação do Projeto:

O Projeto está bem elaborado, com objetivos claramente definidos e metodologia adequada às condições da pesquisa.

Objetivo da Pesquisa:

O objetivo da pesquisa é claro e compatível com a proposta da Pesquisa. Está, também, adequado à metodologia proposta pelo(s) pesquisador(es).

\section{Avaliação dos Riscos e Benefícios:}

Os riscos, mínimos para os participantes, foram adequadamente apresentados. Também está claro para os participantes os benefícios da participação e adesão à pesquisa.

Comentários e Considerações sobre a Pesquisa:

O Projeto de pesquisa está adequadamente fundamentado, teórica e metodologicamente, com objetivos bem definidos e metodologia condizente com o projeto proposto.

Considerações sobre os Termos de apresentação obrigatória:

O TCLE está redigido em linguagem adequada, passível de ser claramente entendida pelos responsáveis dos participantes da pesquisa. Além disso, os riscos e benefícios estão claramente definidos, bem como as condições de adesão e desistência dos participantes. Também está definido claramente o local para eventual atendimento dos participantes, caso haja esta necessidade.

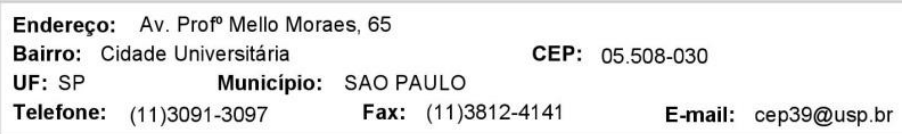




\section{USP - ESCOLA DE EDUCAÇÃO FÍSICA E ESPORTE DA UNIVERSIDADE DE SÃO}

Continuação do Parecer: 2.865 .152

Recomendações:

Não há nenhuma recomendação adicional a fazer

Conclusões ou Pendências e Lista de Inadequações:

Não há pendências ou inadequações. Projeto correto e adequado.

Considerações Finais a critério do CEP:

Este parecer foi elaborado baseado nos documentos abaixo relacionados:

\begin{tabular}{|c|c|c|c|c|}
\hline Tipo Documento & Arquivo & Postagem & Autor & Situação \\
\hline $\begin{array}{l}\text { Informações Básicas } \\
\text { do Projeto }\end{array}$ & $\begin{array}{l}\text { PB_INFORMAÇÕES_BÁSICAS_DO_P } \\
\text { ROJETO_1115411.pdf }\end{array}$ & $\begin{array}{c}21 / 06 / 2018 \\
16: 48: 33\end{array}$ & & Aceito \\
\hline $\begin{array}{l}\text { Projeto Detalhado / } \\
\text { Brochura } \\
\text { Investigador }\end{array}$ & Projeto_mestrado.docx & $\begin{array}{c}21 / 06 / 2018 \\
16: 44: 06\end{array}$ & Go Tani & Aceito \\
\hline $\begin{array}{l}\text { TCLE / Termos de } \\
\text { Assentimento / } \\
\text { Justificativa de } \\
\text { Ausência }\end{array}$ & TCLE.doc & $\begin{array}{c}21 / 06 / 2018 \\
16: 40: 26\end{array}$ & Go Tani & Aceito \\
\hline Folha de Rosto & folha_de_rosto.pdf & $\begin{array}{c}21 / 06 / 2018 \\
16: 39: 00 \\
\end{array}$ & Go Tani & Aceito \\
\hline
\end{tabular}

Situação do Parecer:

Aprovado

Necessita Apreciação da CONEP:

Não

SAO PAULO, 31 de Agosto de 2018

Assinado por:

Edilamar Menezes de Oliveira

(Coordenador)

Endereço: Av. Profo Mello Moraes, 65

Bairro: Cidade Universitária

CEP: $\quad 05.508-030$

UF: SP Município: SAO PAULO

Telefone: (11)3091-3097

Fax: (11)3812-4141

E-mail: cep39@usp.br

Página 02 de 02 


\section{Anexo 3 - Protocolo de avaliação do golpe o soto gari (GOMES, 2007)}

\section{ANEXO IX \\ PROTOCOLO DE AVALIAÇÃO DO GOLPE O SOTO GARI}

A avaliação é subdividida em duas partes, de acordo a divisão do golpe originalmente.

a. kuzushi: desequilíbrio

b. tsukuri: encaixe ou aproximação

Pontuação: (1) Ruim; (2) Regular; (3) Bom; (4) Ótimo

\section{a. KUZUSHI}

O trabalho de gola, representado na figura abaixo, assemelha-se ao "tranco" que se aplica a uma vara de pescar quando se fisga um peixe.

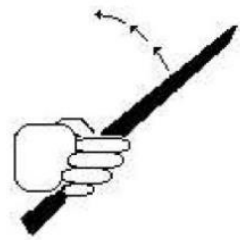

1. Ruim: não existe desequilíbrio, o uke (em quem esta sendo executada a ação) está em shi zen hontai (posição natural frontal), e o peso do corpo está distribuído nas duas pernas, como na figura abaixo.

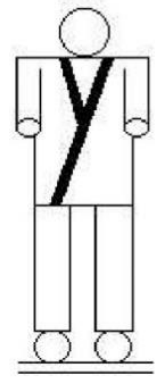


2. Regular: nota-se algum desequilíbrio na manga, por volta de $45^{\circ}$ de abdução do braço em relação ao tronco. Porém, o peso corporal está ainda distribuído nas duas pernas, conforme figura a seguir.

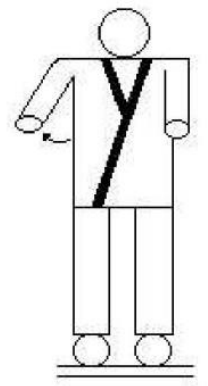

3 I. Bom: a manga está à $90^{\circ}$ de abdução em relação braço e o corpo, começa aparecer algum "trabalho" de gola, e o peso do corpo já começa a predominar em uma perna, de acordo com a figura.

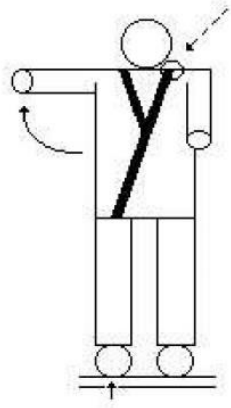


3 II. Bom: pode vir acontecer o desequilíbrio, como na figura abaixo. Há um trabalho eficiente de manga, porém com o braço um pouco abduzido em relação ao tronco. A manga está desequilibrando direcionada ao cotovelo para o solo, existe pouco "trabalho" de gola, em compensação com esse tipo de desequilíbrio de manga, o uke esta com o peso do corpo predominando na perna direita.

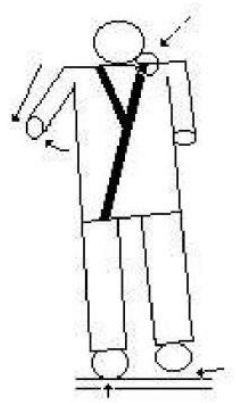

4. Ótimo: idem a (3 I), mas existe um ótimo trabalho de gola, e o uke está apoiado com o peso em uma perna só, como na figura abaixo.

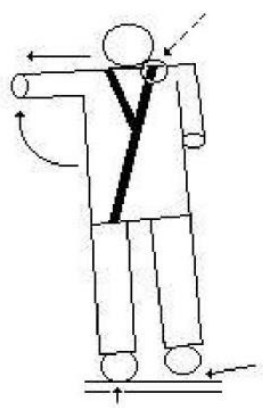




\section{b. TSUKURI}

uke: a pessoa em que a ação está sendo executada. O pé hachurado é o esquerdo, e o em branco representa o pé direito.

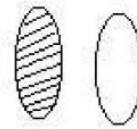

tori: quem aplica a ação, o pé hachurado é o esquerdo. E o pé em branco se refere ao direito

1. Ruim: não executa a aproximação ou encaixe. O tori não sai de sua postura, e executa o golpe só com braço.
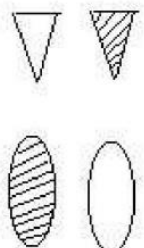

2. Regular: Não há aproximação da perna, principalmente por causa do braço do tori estar hiper-extendido. A conseqüência é apoiar o pé no solo que está demarcado com um círculo, conforme figura.

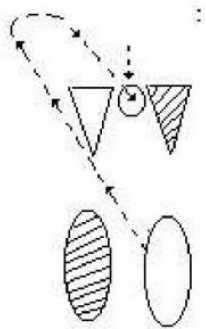


3. Bom: já avançando a perna de apoio, no caso a esquerda. Ocorre alguma aproximação, o tori "chuta" a perna livre para frente, e, ao voltar, "chuta" a mesma para trás, ao entrar em contato com a perna do uke, apóia a perna livre no solo. Essa ação está representada pelo círculo na figura abaixo.

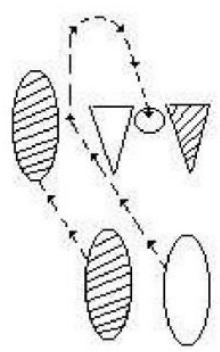

4. Ótimo: há o encaixe ou aproximação, a perna de apoio (no caso a esquerda) avança, e a perna livre (direita) efetua um "chute" para frente, e, voltando para trás, ao entrar em contato com a perna do uke, continua a efetuar o "chute" para trás, terminando o movimento com a perna sem estar em contato com o solo, representado pelo quadrado na figura abaixo

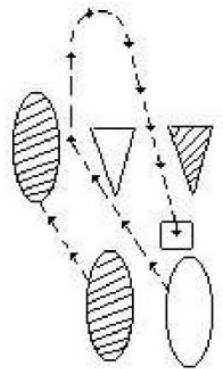

